\title{
RECORDANDO A UN IMPERIO PASTORIL: LA SOCIEDAD EXPLOTADORA DE TIERRA DEL FUEGO (1893-1973)
}

MATEO MARTINIC B*

\section{RESUMEN}

La Sociedad Explotadora de Tierra del Fuego fue durante su prolongada vigencia tanto la mayor tenedora de tierras (como propietaria y arrendamientos), cuanto la más importante productora ganadera de Chile, por la cuantía y calidad de sus producción. Como tal fue, asimismo, una empresa determinante para el desarrollo económico durante el lapso que transcurrió entre 1893 y 1973, destacándose por su impronta progresista. El artículo analiza lo que fuera su existencia, con una visión reflexiva hecha desde la perspectiva histórica sobre lo que fueron sus características definitorias en lo referido al proyecto colonizador que le diera origen, a la nacionalidad de la entidad y la formación y evolución de su patrimonio fundario; a la tecnología productiva y sus resultados, a su gente en el transcurso del tiempo, y a los avatares finales que concluyeron con la reforma agraria, hecho que determinó su extinción legal; y, por fin, a lo que puede ser tenido como su legado histórico.

PALABRAS CLAVE: crianza ovina, latifundio, Magallanes.

\section{REMEMBERING A SHEEPFARMER IMPERIUM: THE SOCIEDAD EXPLOTADORA DE TIERRA DEL FUEGO (1893-1973)}

\begin{abstract}
The Sociedad Explotadora de Tierra del Fuego during its long life was both the largest land holding (as owner and leases), and the largest producer of livestock in Chile, in amount and quality of its production. As such, it was also a crucial undertaking for economic development during the period that elapsed between 1893 and 1973, highlighted by its progressive mark. The article discusses their existence, from an historical perspective made with a reflective view on what were its defining characteristics with regard to the settlement project that gave it origin, with the nationality of the entity and the formation and evo-
\end{abstract}

* Profesor Emérito e investigador, Centro de Estudio del Hombre Austral, Instituto de la Patagonia, Universidad de Magallanes. Punta Arenas, Chile. mateo.martinic@umag.cl. 
lution of their founded heritage; to the production technology and its outcomes, its people over time, as the final avatar who finished with land reform, which determined its legal termination and, finally, what can be had as its historical legacy.

KEY WORDS: sheepfarming, latifundium, Magellan Territory.

\section{INTRODUCCIÓN}

Hace un siglo cabal la Sociedad Explotadora de Tierra del Fuego, por entonces la empresa ganadera más importante de la Patagonia austral a ambos lados de la frontera internacional, y aun de Chile, alcanzaba gracias a una acertada y feliz gestión de sus ejecutivos la cima de sus posesiones fundiarias, al totalizar la tenencia de nada menos que 3.000.000 de hectáreas de campos para la explotación pastoril, circunstancia que manifestaba de modo tangible la fuerza económica que la misma poseía y el consiguiente poder que de ello derivaba y que se hacía notar dentro y fuera de las fronteras territoriales. A menos de dos décadas de su constitución legal en 1893, se alzaba la entidad como la expresión más conspicua del empresariado que dominaba en los campos patagónicos por su eficiente manejo tecnológico, por la cuantía de sus recursos y sus envidiables resultados productivos. En cierto modo, la misma manifestaba el vigor creativo que en lo económico destacaba al Territorio de Magallanes en el conjunto nacional chileno. Tal era su importancia que puede estimarse -en los términos comprensivos actuales- al valorarse la concurrencia de las diferentes actividades económicas en la producción interna bruta de Magallanes, que si la ganadería ovina (lana y sus derivados industriales) lo hacía en un porcentaje que superaba largo el 90\%, en la misma participaba la Sociedad Explotadora de Tierra del Fuego en la mitad, si no más, de ese porcentaje. Era así esta empresa un protagonista importantísimo en la vida económica territorial, de modo directo (productivo) e indirecto (generadora de servicios y negocios), con su no menos relevante correlato social como fuente de trabajo permanente y ocasional, que la mantendría por unas seis décadas como la mayor empleadora de la región, con remuneraciones y condiciones laborales por lo común satisfactorias.

En tal posición y rol pudo ser respetada y admirada, o detestada por igual durante algunos momentos en el seno de la comunidad magallánica, sentimientos que de algún modo compartieron dos generaciones y que en la memoria popular sobrepasarían la propia vigencia empresarial. Vista como un símbolo de un poder económico omnímodo o como acaparadora insaciable de tierras; como manifestación paradigmática de eficiencia productiva o como entidad extranjerizante lesiva para la chilenidad de Magallanes, como añorada empleadora o como quiera que se la considerara a lo largo de su octogenaria existencia, su presencia y actividades no dejaron indiferentes a sus contemporáneos.

Habiendo participado hace ya tiempo de algunas opiniones con las que se trataba con acritud su accionar empresarial, corridas casi cuatro décadas desde su desaparición de la escena productiva regional, nos ha parecido cosa necesaria revisar aspectos salientes de lo que fuera la trayectoria de la Sociedad Explotadora de Tierra del Fuego, desde una perspectiva más tranquila y serena, y por tanto más objetiva, repensando e interpretando opiniones propias y ajenas, y recogiendo los sentimientos acumulados por la tradición local, generando así reflexiones y consideraciones que pueden ser de utilidad para la historia regional magallánica en lo tocante al significado y al sentido de una entidad empresarial que no tuvo igual en el acontecer del sur de América.

\section{PROYECTO COLOSAL DE COLONIZACIÓN GANADERA}

Avanzada la década de 1880 la inmensidad oriental del Territorio de Magallanes, esto es, la parte que la experiencia de poco más de cuatro décadas de vida permanente ${ }^{1}$ mostraba como apta para ser habitada y explotada económicamente, comenzaba a ser ocupada paulatinamente por los

1 Debe tenerse presente que el establecimiento jurisdiccional de Chile, origen del poblamiento foráneo del territorio austral, había tenido inicio en 1843. 
primeros colonos. La escasa población no aborigen que por entonces enteraba las dos mil almas ${ }^{2}$, y la insuficiencia de recursos para cualquier emprendimiento económico de cierta proporción como podía serlo alguno del género colonizador; la vastedad del espacio geográfico disponible y la reciente certidumbre de ser la crianza ovina la más productiva y eficiente para aprovechar las ricas pasturas del ambiente estepario ${ }^{3}$, y por fin la tranquilidad que trajo el Tratado de Límites entre Chile y Argentina para la solución de la disputa por el dominio de la Patagonia oriental y la Tierra del Fuego (1881) en cuanto permitía a cada país disponer libremente de su patrimonio fundiario, habían concurrido, de diferente modo, a la lentitud inicial del proceso de ocupación. Pero pasada la primera mitad de la década el mismo cobró vigor y proporciones tales que no pararía sino hasta completarse virtualmente la ocupación del ecúmene al promediar la primera década del siglo XX. En esa vorágine de emprendimiento debe ser entendida la ocupación colonizadora de la Tierra del Fuego, que desde un principio tuvo un carácter diferenciado respecto de lo que se había dado con antelación, como se daría después en contemporaneidad en la tierra firme de Patagonia, pues consagraría para la historia el sistema del latifundio como forma de tenencia agraria.

La calidad pastoril de los terrenos esteparios y de ecotono estepa/bosque de la isla grande fueguina había sido advertida en el transcurso de la exploración de conocimiento practicada por el capitán Ramón Serrano Montaner, por encargo del gobierno de Chile (enero 1879), pero no fue sino hasta que se registró la primera petición para una concesión de colonización que el proceso de ocupación generó interés. La misma, elevada al gobierno del Presidente Domingo Santa María por los hermanos César, Augusto y Hernán Wehrhahn, comerciantes de Valparaíso (aunque con su casa matriz en Hamburgo) se hizo efectiva en 1883 sobre una extensión de 123.000 hectáreas en el sector noroccidental de la Tierra del Fuego, entre las bahías de Gente Grande y Porvenir. El arrendamiento fue concedido por un plazo de veinte años. Es posible

\section{Censo Nacional de 1885}

Las primeras ovejas fueron traídas desde las islas Malvinas a fines de 1876 y tras su aclimatación se sucedieron las demandas de terrenos pastoriles y las consiguientes importaciones de animales ovinos. que ese interés fuera originado por una sugerencia de Rodolfo Stubenrauch, el inteligente factor que la firma Wehrhahn Hnos. tenía en Punta Arenas ${ }^{4}$, quien se habría enterado de la sagaz observación de Serrano a poco de arribar a la colonia magallánica, lo que prueba que la noticia había cobrado difusión vecinal. De hecho el mismo Stubenrauch entraría a participar en la sociedad constituida para la explotación pastoril (Wehrhahn Hnos. y Cía.) $)^{5}$. Entre cuantos otros pudieron participar de la novedad estuvieron José Nogueira, a la sazón el empresario más importante de Magallanes y amigo de Serrano, y el grupo familiar Braun Hamburger relacionado con Nogueira por una amistad de larga data, que se afirmaría sólidamente a poco andar luego del matrimonio del mismo con Sara, la hija mayor de Elías y Sofía Braun (1887). Allí y con seguridad desde antes de esta última circunstancia, y con mayor razón luego de la boda, debió verse la posibilidad de colonizar en Tierra del Fuego, en una consideración referida a la generación de negocios que debió darse recurrentemente en aquellos tiempos y ambientes entre los contados empresarios de Punta Arenas que disponían de recursos para iniciar actividades económicas de envergadura. Tal iniciativa se concretó, como es sabido, con la primera concesión de arrendamiento de 180.000 hectáreas de campos fueguinos hecha a nombre de Nogueira (Decreto Supremo de 22 de abril de 1889) y una segunda de 170.000 cuyo titular fue Mauricio Braun, cuñado y hombre de confianza de aquél, actuando para el caso como su testaferro (Decreto Supremo de 15 de noviembre de 1889).

4 Natural de Prusia, en el Imperio Alemán, llegó a Punta Arenas hacia 1880 ó 1881 enviado por la firma con la que trabajaba para hacerse cargo de su establecimiento comercial fundado en 1869 . Hombre instruido y culto, no tardó en hacerse notar por su empuje empresarial y en relacionarse con la reducida sociedad pequeño-burguesa del Territorio. Sus negocios desde entonces y para el porvenir estuvieron particularmente relacionados con el distrito de Última Esperanza y cubrieron ámbitos como el comercio, la navegación, la ganadería y la industria. Su solvencia y su prestigio le llevaron a desempeñar el cargo de cónsul del Imperio Alemán en Magallanes, que ejerció durante más de cuatro décadas, como también el de Gran Bretaña.

5 Sobre esa base empresarial se constituyó más tarde (1888) la Sociedad Ganadera Gente Grande en la que concurrieron los capitales de Stubenrauch y los de Louis Baillon y Ernesto W. Hobbs, aquél un estanciero de las Islas Malvinas y éste inmigrante británico radicado en Punta Arenas con una estadía previa en el dominio colonial mencionado. 
Si tales concesiones abrieron el apetito fundiario del empresario en demanda de un bocado mayor, esto es, nada menos que el resto del territorio fueguino disponible apto en apariencia para el establecimiento de la industria pastoril, dicha posibilidad debió ser coincidente con una idea semejante que Ramón Serrano Montaner se atribuiría más tarde y que se hizo efectiva en forma de sugerencia hecha al Presidente de la República de la época, don José Manuel Balmaceda.

En efecto, según recordaría aquél casi medio siglo después, reflexionando sobre el hecho de que las tres concesiones conocidas habían terminado en manos de entidades extranjeras ${ }^{6}$, y estimando como lesivo tal hecho para el mejor interés nacional, habría discurrido en consecuencia que el único modo de evitar que esa isla [Tierra del Fuego] cayese toda ella en poder de extranjeros extraños al país era entregar la explotación de los terrenos vacantes de la isla a una sociedad anónima chilena, que no pudiese cambiar de domicilio ni nacionalidad sin anuencia del Gobierno, y donde tuvieran cabida los capitalistas chilenos chicos y grandes...?.

Teniendo como tuvo buena llegada al ilustre mandatario, Serrano le hizo ese planteamiento a Balmaceda, quien convino en que tal concesión de hacerse efectiva, debía serlo en favor de una sociedad constituida en Chile y con capitales nacionales. Así las cosas, el antiguo marino se habría dado a la tarea de encontrar un capitalista capaz de reunir por sí mismo o con otros el cuantioso capital suficiente para la gran empresa pastoril fueguina $y$

6 La concesión de Gente Grande se hallaba como se ha visto en manos de una sociedad chilena constituida en 1888 , y en cuanto a las otras dos, Nogueira sobre su base había negociado el traspaso a dos sociedades constituidas en Londres, The Tierra del Fuego Sheep Farming Company y The Philip Bay Sheep Farming Company, en la que aquél conservaba un tercio del correspondiente capital. Había sido determinante en tal decisión el estado de la salud del pionero, que se agravaba de día en día, del mismo modo que la necesidad de tener las manos libres para ocuparse de la tercera gran concesión que recibió en 1890, como lo exigía perentoriamente el consiguiente compromiso contraído con el Supremo Gobierno. Los socios de Nogueira en esas entidades integraban el grupo Waldron \& Wood, capitalistas británicos que tenían intereses fundiarios en Patagonia (Véase nuestra obra Nogueira el pionero (edición de la Universidad de Magallanes, Punta Arenas, 1986).

7 "La chilenización de Magallanes", artículo de su autoría publicado en la Revista Chilena de Historia y Geografía, tomo LXXVII (Santiago, 1935), pág. 21. lo encontró en Nogueira, que por aquel tiempo se hallaba hospedado en su casa de Santiago, conjuntamente con su esposa Sara lo que de suyo da cuenta del grado de amistad que tenían. De allí la sorprendente concesión hecha por el gobierno de Balmaceda en favor de Nogueira sobre un total de 1.009.000 hectáreas de campos fueguinos, en un arrendamiento por veinte años (Decreto Supremo de 9 de julio de 1890), con el compromiso de formar dentro de un plazo determinado una sociedad, obviamente chilena, para llevar adelante el proyecto de explotación pastoril.

El señor Nogueira murió antes que pudiese actuar en la formación de la sociedad; pero antes de morir y a fin de que yo pudiese continuar actuando en la organización de la Sociedad, el señor Nogueira me cedió la tercera parte de sus derechos por lo que a él le costaban, agregaría Serrano. ${ }^{8}$

Fernando Durán, periodista que en 1943 recibió el encargo de escribir la historia del medio siglo de la Sociedad Explotadora de Tierra del Fuego, consignaría en su obra que la iniciativa de la concesión le cupo a Nogueira y que la ocasión para plantearla al Presidente Balmaceda se le dio durante un encuentro de ambos en las Termas de Cauquenes, con el resultado conocido.

Comentando ambas aseveraciones, cabe abundar acerca de la propiedad de los dichos de Serrano, como de la circunstancia del acceso de Nogueira a Balmaceda relatada por Durán.

En cuanto a lo primero, años atrás dimos a conocer una información que permite pensar con fundamento en que a lo menos para 1886 Nogueira ya cavilaba sobre un negocio pastoril de gran envergadura ${ }^{9}$ y que lo gestionaba al parecer a través de su amigo Oscar Viel, antiguo Gobernador de Magallanes y por entonces a cargo de la Mayoría General de Marina y como tal el segundo hombre de la Armada de Chile, posición indudablemente ventajosa como para acceder con cierta facilidad a la persona del Presidente de la República. Así y sin poder precisar sobre si ese "negocio pastoril" se refiriera a las primeras concesiones o a la última, o inclusive a las tres como elementos de un único gran proyecto, matizando el dicho de Serrano en cuanto a su participación determinante en tan importante

\footnotetext{
Id. pág. 22.

9 Véase nuestra obra citada, págs. 115 y 116.
} 
gestión, hay que considerar la de Viel y tal vez la de otro algún otro antiguo amigo o conocido de Nogueira altamente colocado, como pudo ser el caso de Robustiano Vera, abogado de prestigio que había atendido profesionalmente al portugués años antes y que por entonces era magistrado de la Corte Suprema de Justicia. Tampoco puede excluirse la posibilidad de que en tan importante asunto para Nogueira intervinieran varias otras personas.

Tocante a la aseveración de Fernando Durán, es evidente que la misma pudo recogerla de la tradición que hubo de mantenerse por largo tiempo en el seno de la Sociedad Explotadora de Tierra del Fuego, o bien, cosa posible, que tal noticia fuera el fruto de una conversación que ese autor pudo sostener con doña Sara Braun, la viuda del pionero, en su alta ancianidad. En todo caso es razonable pensar que el encuentro entre el Presidente Balmaceda y el empresario magallánico debió darse no por obra de la casualidad, sino que por la intermediación de personas conocidas de ambos. En fin, lo cierto es que el Presidente pudo enterarse en conversación con Nogueira (de la que sin duda participó doña Sara), acerca de lo que era su proyecto y recibir del mandatario el aliento para su adelanto. Ello no quita que además y corriendo la solicitud pertinente, otras personas intervinieran en su mejor curso, entre las que debió hallarse en rango importante Ramón Serrano Montaner. Así se explica la gratitud que pudo guardarle Nogueira y la consiguiente cesión, en retribución, que hiciera en favor del mismo de un tercio en la futura sociedad pastoril, antes de su fallecimiento.

Resumiendo, la observación original de Serrano acerca de la aptitud pastoril de los campos fueguinos, reiterada en el ambiente de sus amistades, entre las cuales calificaba José Nogueira, debió ser especialmente considerada y luego madurada por este empresario, evaluada por sus consejeros y colaboradores, que los tenía y buenos, y madurada en el seno familiar, cobrando al fin la forma de una propuesta genial y ambiciosa que resultó exitosa iy vaya que lo fue!

La genialidad y ambición la hallamos en el hecho de versar la misma sobre un proyecto de colonización en un territorio extenso y virtualmente virgen, cuyo carácter insular y la circunstancia de encontrarse poblado por indígenas de índole insuficientemente conocida, agregaban costo y riesgo adicionales a una empresa que de suyo los tenía; y en el hecho de no arredrarse el proponente ante la magnitud del esfuerzo que la misma suponía y ante la incertidumbre de disponer del suficiente capital para enfrentarla con seguridad de éxito.

Proyecto de envergadura colosal por donde se lo considere, asombra todavía a un siglo y cuarto o más de haber sido concebido, habida cuenta de la escasez de recursos y medios de apoyo que mostraba el remoto y aislado Territorio de Magallanes de la época, una real tierra de frontera donde la aventura y la temeridad tenían amplísimo (e insospechado) campo para darse y desarrollarse. Quien lo había concebido tenía su propia épica pionera: arribado cosa de un cuarto de siglo antes, analfabeto y sin recursos, apenas con alguna experiencia de vida marinera, al cabo de ese lapso había superado la mezquindad del medio y sus propias limitaciones personales hasta ser reconocido como un hombre próspero, el mayor empresario de la antigua colonia magallánica, con negocios cinegéticos, navieros, comerciales, mineros y ganaderos. En digna gesta personal todo lo había conseguido a costa de trabajo, sacrificio, constancia y tenacidad, y la infaltable cuota de suerte que suele darse para muchos.

\section{II. ¿UNA SOCIEDAD CHILENA O BRITÁNICA?}

A los problemas naturales de toda sucesión, la de José Nogueira añadió el particular derivado de la cesión que éste había hecho a Serrano sobre un tercio de sus derechos en la gran concesión fundiaria fueguina, con el compromiso según este ultimo de llevar adelante la formación de la sociedad que debía hacerse cargo de la explotación económica. De este acto, sin duda reservadísimo, estuvo enterada Sara, la esposa del primero y fue juramentada en cuanto a su absoluta reserva. Pero, tras la muerte del pionero, abrumada como pudo estar por la situación compleja sobreviniente no dudó en participar el asunto a su hermano y consejero Mauricio. Puestos de acuerdo ambos en cuanto a la conveniencia de sacar de en medio a Serrano, así efectivamente se consiguió tras una negociación áspera e ingrata, en cuya virtud Serrano convino en no llevar adelante su exigencia de cumplimiento del compromiso establecido con Nogueira a cambio de la reserva de cien acciones del capital de la sociedad que debía constituirse, resultado que no acabó de conformarlo 
y que significó el enfriamiento de su relación con los hermanos Braun Hamburger y, al fin, la ruptura total entre uno y otros.

El arreglo debió tomar su tiempo y entre tanto, siempre según los dichos de Serrano en sus recuerdos citados, él y Mauricio Braun asumieron el trabajo de organización de la sociedad y estando en ello, aquél habría recurrido a Francisco Newman, mencionado como Presidente del Banco de Chile en Valparaíso, aunque es probable que fuera el gerente local de la entidad, y tras informarlo del asunto habría conseguido su colaboración, que se hizo efectiva interesando en él a Peter Mc Clelland, cabeza de la firma Duncan, Fox \& Co. Ltd. en Chile, al que Serrano asigna equivocadamente la segunda posición directiva de la empresa en el país.

La intervención atribuida a Newman es toda una novedad, al parecer no recordada por la tradición institucional, que sí, en cambio, registraría la intervención que cupo a Mauricio Braun en la decisiva gestión para interesar a Mc Clelland en el asunto, como lo consignaría a su tiempo Fernando Durán en su obra citada, también Tom P. Jones ${ }^{10}$ y el mismo Braun en sus propios recuerdos ${ }^{11}$, todo lo cual nos ha llevado a valorizar la intervención de este último para ganar la voluntad y disposición del ejecutivo británico, que resultaría determinante para la exitosa constitución legal de la Sociedad Explotadora de Tierra del Fuego ${ }^{12}$. Está claro que en esto como en otros aspectos de la materia la memoria pudo fallarle a Serrano al tiempo de escribir sus recuerdos, a menos que las afirmaciones comentadas fueran hechas con la intención de destacar para la historia su participación en la materia de que se trata. De cualquier modo, debe aceptarse que la tarea organizativa pudo exceder la propia capacidad del joven y talentoso empresario magallánico y así el mismo debió recurrir a la colaboración y asesoría de terceros

10 Patagonian Panorama (London, 1961). Jones tuvo una prolongada residencia en Magallanes y se desempeñó como gerente del Frigorífico de Río Seco, el más importante de la Región y propiedad de la firma inglesa The South American Import Export Syndicate, y en simultaneidad sirvió el cargo de Cónsul de Gran Bretaña en Magallanes. Por su posición conoció y trató largamente a Braun y Mc Clelland.

11 Armando Braun Menéndez, Memorias de una vida colmada (Buenos Aires, 1985).

12 Véase nuestra obra, Menéndez y Braun prohombres patagónicos (Ediciones de la Universidad de Magallanes, Punta Arenas, 2001). para encaminar las gestiones y negociaciones que fueron necesarias para dar culminación satisfactoria al compromiso contraído por José Nogueira al tiempo de la concesión del gran arrendamiento fueguino.

Aclarado el punto y reconociéndose por tanto el esfuerzo y la habilidad puestos por Mauricio Braun en el importante negocio, cabe ocuparse de otros dos aspectos que calificarían a la Sociedad Explotadora desde un principio y referidos a la propiedad del capital y a la sólida vinculación social y política que la entidad logró establecer.

Tocante a lo primero, la obligación contraída por el beneficiario de marras no daba lugar a equívocos: la sociedad debía ser chilena por capital y domicilio legal. Y tal ocurrió en efecto. EI capital inicial fue fijado en $\$ 1.250 .000$, dividido en 2.500 acciones con un valor de $\$ 500$ cada una, y quedó efectivamente enterado al tiempo de la suscripción de la escritura pública fundacional (31 de agosto de 1893). Los principales accionistas eran Sara Braun viuda de Nogueira, Mauricio Braun y el grupo familiar Braun Hamburger, además de Juan Blanchard (socio de Braun \& Blanchard) y otras personas de Punta Arenas que reunían en conjunto casi la mitad del capital social. Con ellos, más las acciones de Ramón Serrano Montaner, Guillermo Wilms, Cruz Daniel Ramírez y Juan y Gustavo Oehninger (100 acciones cada uno) y de otros varios accionistas menores de Valparaíso, bastó para dar mayoría a la propiedad de chilenos y por tanto el carácter de nacional al capital de la compañía. La participación accionaria de Duncan, Fox \& Co. Ltd. fue ciertamente importante pero en un porcentaje inferior a la mitad del capital suscrito y pagado, como debía ser.

Sin embargo de la chilenidad del capital, fue corriente oír y leer en la época y hasta muchos años después acerca de la "compañía inglesa", dándose a entender con ello que lo era por la propiedad del capital y la nacionalidad mayoritaria de sus ejecutivos y directores. Pero se trató de una versión desprovista de fundamentos, por cuanto se basaba más en la apariencia que en la realidad, y que por cierto, tenía mucha fuerza según se verá.

Para 1909, año para el cual hemos podido disponer de una fuente informativa irremplazable como es la Memoria y Balance de la Sociedad Explotadora de Tierra del Fuego, el dominio accionario se repartía entre 1.264 accionistas, en su mayoría con residencia en Chile (principalmente en Punta 
Arenas, Valparaíso y Viña del Mar), de los que los principales eran Sara Braun viuda de Nogueira (82.750 acciones), Mauricio Braun (59.800 acciones), José Menéndez (44.600 acciones), Ramón Serrano Montaner (22.000 acciones) y Enrique Richard (19.000 acciones). La casa Duncan Fox por su parte reunía 108.210 acciones. La situación de predominio de la casa mercantil británica y del, por así llamarlo, "Grupo Punta Arenas" (Sara Braun, Mauricio Braun, otros parientes, José Menéndez, Braun \& Blanchard), caracterizó el primer tiempo social pero pasó a variar pasado el primer cuarto de siglo de existencia legal de la compañía, época hacia la que la antigua firma británica vendió, o más posiblemente, traspasó a una entidad chilena el grueso de su importante paquete accionario.

Así, para 1920, sobre el treinta por ciento del capital-entonces 1.800.000 libras esterlinas dividido en 1.800.000 acciones de una libra- se repartía entre trece personas naturales y jurídicas (637.039 acciones), de los que las más importantes eran la Compañía de Custodia de Valores (210.816 acciones), Sara Braun (94.400 acciones), Mauricio Braun (70.500 acciones), Fernando José Irarrázaval (50.000 acciones), José Menéndez (en realidad su sucesión pues aquél había fallecido en 1918, 38.100 acciones); Banco de A. Edwards y Cía. (43.611 acciones), Banco AngloSudamericano (29.292 acciones), Banco Español de Chile (19.282 acciones) y Santiago Ossa (20.000 acciones). Entonces Duncan Fox y Cía. figuraba en los registros sociales con 16.038 acciones.

Pasada la mitad del siglo de existencia de la Sociedad Explotadora de Tierra del Fuego, en 1947 la propiedad accionaria (el total de 1.800 .000 acciones) se repartía entre 2.149 accionistas, de los que 1.956 eran chilenos (1.442.827 acciones) y 193 extranjeros, mayoritariamente británicos (357.173 acciones) lo que daba cuenta de una sostenida tendencia de aumento de aquéllos en la propiedad del capital social. Del total en manos extranjeras, Duncan Fox \& Co. Ltd. poseía 106.741 acciones y el Banco de Londres y América del Sud Limitado, 149.900, proporciones todavía importantes en el conjunto.

Para septiembre de 1950 el monto del capital social no había variado, aunque sí lo había hecho el número de acciones en que el mismo se dividía, ahora 7.200.000, con un valor nominal de cinco chelines cada una. La propiedad se dividía entre 2.625 accionistas, de los que 2.356 eran chilenos, esto es el 80,16\% (5.771.414 acciones) y 260 eran extranjeros, o sea el 19,84\% (1.428.586 acciones). Doña Sara Braun, ya nonagenaria, seguía siendo por lejos la persona natural con más acciones (350.000), en tanto que entre las personas jurídicas propietarias estaban el Banco de Londres y América del Sud Limitado (521.636 acciones) y Duncan Fox \& Co. Ltd. (439.332 acciones), uno y otra de nacionalidad británica, lo que en conjunto con otros 81 accionistas de ese origen que eran dueños de 172.104 acciones, representaba el 15,7\% de la propiedad del capital.

Finalmente, la septuagésima quinta Memoria anual (1968) resulta de interés para conocer cómo hacia su época final la Sociedad Explotadora de Tierra del Fuego tenía repartida la propiedad del capital. Este entonces era de 77.765.540 escudos (moneda de la época), dividido en otras tantas acciones de un escudo cada una, cuya pertenencia era la siguiente:

Tabla 1.

\begin{tabular}{|c|c|c|c|}
\hline & $\begin{array}{l}\text { PERSONAS } \\
\text { NATURALES }\end{array}$ & ACCIONES & PORCENTAJE \\
\hline 6136 & $\begin{array}{l}\text { Personas con } 1 \\
\text { a } 20.000 \text { accs. }\end{array}$ & 19.142 .242 & $24,61 \%$ \\
\hline 512 & $\begin{array}{l}\text { Personas con más } \\
\text { de } 20.000 \text { accs. }\end{array}$ & 24.270 .106 & $35,07 \%$ \\
\hline \multirow[t]{2}{*}{6.648} & & 46.412 .348 & \\
\hline & $\begin{array}{l}\text { PERSONAS } \\
\text { JURÍDICAS }\end{array}$ & & \\
\hline 24 & $\begin{array}{c}\text { Bancos nacionales } \\
\text { y extranjeros }\end{array}$ & 4.079 .947 & \\
\hline 2 & Bolsas de comercio & 3.150 .029 & \\
\hline 12 & Cajas de Previsión & 1.463 .761 & \\
\hline 117 & $\begin{array}{c}\text { Compañías } \\
\text { de seguros }\end{array}$ & 5.101 .087 & \\
\hline 3 & Comunidades & 121.269 & \\
\hline 65 & $\begin{array}{c}\text { Congregaciones } \\
\text { Religiosas }\end{array}$ & 769.357 & \\
\hline 8 & $\begin{array}{l}\text { Establecimientos } \\
\text { de Instrucción }\end{array}$ & 489.706 & \\
\hline 26 & Fundaciones & 1.561 .377 & \\
\hline 51 & $\begin{array}{l}\text { Instituciones de } \\
\text { Beneficencia }\end{array}$ & 885.427 & \\
\hline 30 & Instituciones Varias & 1.098 .691 & \\
\hline 59 & Sociedad Anónimas & 9.015 .891 & \\
\hline 38 & $\begin{array}{l}\text { Sociedades } \\
\text { Comerciales }\end{array}$ & 2.419 .231 & \\
\hline 3 & $\begin{array}{l}\text { Sociedad de } \\
\text { Capitalización }\end{array}$ & 1.197 .419 & \\
\hline 438 & & 31.353 .192 & $40,32 \%$ \\
\hline
\end{tabular}


Los diez mayores accionistas individuales de la Sociedad poseían entonces acciones que representaban entre el 0,25\% y el 0,52\% del capital social ${ }^{13}$.

Este resumen ilustra elocuentemente acerca de la diversidad de la propiedad accionaria que en cierto modo reflejaba la socialización de la misma, con una abrumadora predominancia de chilenos, reflejo del alto prestigio de la compañía y de la sostenida buena cotización de sus acciones.

Esta revisión a lo largo tres cuartas partes de su octogenaria existencia, da cuenta del hecho de haber sido la Sociedad Explotadora de Tierra del Fuego desde un principio una entidad notoria y mayoritariamente chilena, aunque con una importante porción del capital en manos británicas que pudo variar entre un quinto y un séptimo durante buena parte de su vigencia, porcentaje suficiente para otorgar un poder de control del directorio y, por ende, del manejo de los negocios sociales, situación que sólo varió hacia la década final de su existencia. Y este poder, es claro, reflejaba una imagen de pertenencia extraña, es decir británica, por más que no se ajustara estrictamente a la realidad.

Esta imagen se afirmaba todavía en el hecho de haber estado la conducción ejecutiva, administrativa y técnica (Administración General, administración de estancias y establecimientos y la propia Presidencia de la Sociedad durante los primeros años de su vigencia) virtualmente en manos de británicos durante el primer medio siglo de su existencia ${ }^{14}$ y siempre con abrumadora mayoría hasta el final, con la única variación de que cuando figuraron chilenos, muchas veces se trató, otra vez, de gente con ascendencia británica. Añádase que en todo tiempo las planas operativas medias (subadministración, contaduría e ingeniería) y aun las inferiores (capatacerías) registraron titulares de nacionalidad o ascendencia británica, para acabar de ratificar aquella imagen común de ser la Explotadora "una compañía inglesa". Y por fin, si falta hacía, la lengua inglesa fue en el interior de la

13 75a . Memoria Anual de Ganadera Tierra del Fuego S.A. Fundada en 1893 (Valparaíso, 1968).

14 En ese extenso lapso sólo exceptuaron la norma dos alemanes y un chileno que integraron la nómina de los administradores de estancia. El último fue René Bahamonde Calderón, que tuvo una notable carrera institucional, quien por tal circunstancia sería reconocido desde un principio por el remoquete de "El Chileno". sociedad, por décadas, el idioma de uso corriente en la actividad operativa (y por años en el registro contable), total en los niveles superiores y medios, y parcial en los inferiores. Si aun quedara alguna duda sobre el punto, basta tener presente lo que, además de lo mencionado, debió significar el conjunto de estilos de trabajo, de vida y de convivencia, de gustos y de otra especie, todo en un ambiente very british, para entender que la apariencia del imaginario no carecía de fundamentos, por ser algo real y tangible.

Así, pese a las apariencias, la Sociedad Explotadora de Tierra del Fuego fue en lo formal una entidad chilena, pero aunque no inglesa, es evidente que la misma fue perfectamente funcional al imperialismo económico británico en boga en el mundo al tiempo de su fundación, como lo seguiría siendo durante largo tiempo (exportadora de materias primas y consumidora de manufacturas industriales).

Hemos mencionado asimismo, otro carácter que definió tempranamente el andar de la Sociedad Explotadora de Tierra del Fuego, como fue la potente vinculación que estableció con el ambiente político y social de derecha, esto es, con la oligarquía, y que se mantendría en rango de invariable solidez a lo largo de su existencia histórica. Ello tuvo origen en la perspicacia y habilidad de sus primeros conductores (Mc Clelland y Braun entre otros), que supieron relacionarse con lo más granado del ambiente empresarial de Valparaíso - capital económica de Chile en la época- y con el mundo social de esa ciudad y de la vecina Viña del Mar, y de Santiago, y cultivaron la relación con personajes claves o influyentes de la política y los diferentes gobiernos nacionales. Y mutatis mutandi esa vigorosa y productiva relación se mantendría a lo largo de toda la historia institucional. Basta revisar la nómina de los integrantes de los distintos directorios sociales para constatarlo.

Esas vinculaciones fueron utilísimas y eficaces en todo tiempo y más aun en las épocas de renovación anticipada del gran arrendamiento fueguino y en las épocas de cambios en la orientación política de los gobiernos del país. En ello la sociedad y sus ejecutivos exhibieron una admirable capacidad de ubicación y manejo que contribuyó a fortalecer su imagen pública de entidad con poder real para diferentes efectos $y$, por cierto, para su prestigio. 


\section{FORMACIÓN Y EVOLUCIÓN DE LA TENENCIA FUNDIARIA (1905-1957)}

\section{La jugada magistral de Última Esperanza}

Conocida la magnitud de la gran concesión de 1890 (1.009.000 has.), sobre la misma se inició la explotación económica de sus terrenos a contar de fines de 1893 que en su desarrollo paulatino dio origen a las estancias "Río Pantano", después "Caleta Josefina" (1894), "San Sebastián" (1895) y "Cameron" (1904), situación que se mantuvo invariable hasta 1905. Entonces y en medio de un ambiente pequeño empresarial agitado por las pujas de los colonos originales y de los especuladores interesados en la subasta de tierras fiscales en el distrito de Ultima Esperanza y de su decepcionante resultado (15 de marzo de 1905), una vez conocido el mismo y en la certidumbre de que para poner orden en el asunto y aclarar las cosas habría una intervención del Fisco en el sentido de declarar parcialmente nulo el proceso y llamar a una nueva subasta, el directorio de la Explotadora informado cabalmente sobre la situación vio la oportunidad para la compañía de hacerse con una importante cantidad de excelentes campos de pastoreo, y con gran reserva se decidió elaborar una estrategia de acción y dar los pasos necesarios que aseguraran el triunfo de su interés en la nueva subasta de terrenos fiscales.

En efecto, las negociaciones conducidas por el hábil y sagaz Mc Clelland -quien concibió la que sería una jugada magistral- se hicieron por partida doble: con los personeros de las compañías que se habían creado ex-profeso para participar en el primer remate, a los que se les ofreció una fusión con la Explotadora en condiciones ventajosas para ellos; y con los colonos originales que habían resultado perdedores en la primera subasta, a los que se les ofreció adquirir sus ganados e instalaciones a buen precio. Las gestiones en ambos casos resultaron exitosas y de ese modo la Explotadora, despejado el camino de competidores, se alzó el día del nuevo remate, 25 de septiembre, con 31 de los 35 lotes comprendidos en el acto, con cabida total de 316.975 (que después con una remensura de los campos resaltaría ser de 334.668 hectáreas), vale decir el 90\% de la superficie subastada que incluía los mejores campos ganaderos del distrito. ¡Fue una jugada ciertamente magistral que dejó con un palmo de narices a medio mundo! ${ }^{15}$

Pero el exitoso negocio fundiarios no acabó en ello, pues con posterioridad la Sociedad adquirió a terceros, en propiedad o en derechos ${ }^{16}$, otras 70.543 hectáreas, con lo que su dominio en territorio chileno alcanzó a 405.211 hectáreas, con el añadido gratuito de unas 50.000 hectáreas situadas en la parte norte de su adquisición, en los valles de los ríos Baguales y de las Chinas, que pudo ocupar de facto. Por fin la ya poderosa entidad pastoril compró por aquel mismo tiempo a la Compañía Explotadora de Cerro Palique (sociedad chilena con domicilio en Valparaíso) la estancia "Cerro Palique" situada en territorio argentino, vecino frontera de por medio con parte de los campos recién subastados, añadiendo de esa manera 38.414 hectáreas a su ya importante propiedad, las primeras en suelo extranjero. Para los fines operativos la totalidad de los campos adquiridos se integraron en una gran unidad denominada inicialmente "Sección Ultima Esperanza", que con el transcurso del tiempo dio origen a fracciones menores, las estancias "Cerro Castillo", "Cerro Guido" y "Bories" y "Fuentes del Coyle" (con otras adquisiciones posteriores), esta última en suelo argentino.

\section{De nuevo en el mismo saco}

Suma y sigue. Entre tanto así había ocurrido, también se produjeron interesantes novedades en la Tierra del Fuego. Recordando que allí el pionero Nogueira había recibido por sí y por interpósita persona las primeras dos concesiones en 1889 que en conjunto enteraban 350.000 hectáreas, y que para las correspondientes explotaciones se habían constituido las sociedades The Tierra del

15 Al lector interesado en conocer con mayor detalle lo acontecido en el lapso que medió entre el primer y el segundo remate fundiarios de que se trata, recomendamos consultar nuestra obra Ultima Esperanza en el tiempo (Ediciones de la Universidad de Magallanes, Punta Arenas (2003 (1985)), págs. 129-151.

16 Estos se referían a los terrenos concedidos en arrendamiento especial a Augusto Kark y a doña Mercedes Silva viuda de Señoret, con promesa de venta por parte del Estado, aquél en su condición de pionero poblador (junto con Stubenrauch), y a ésta en su condición de viuda del antiguo Gobernador de Magallanes Manuel Señoret que había favorecido la ocupación colonizadora del importante distrito de Ultima Esperanza. 
Fuego Sheep Farming Company y The Philip Bay Sheep Farming Company, cada una de las cuales dio origen a un gran establecimiento productivo, en 1904 esas compañías se chilenizaron transformándose respectivamente en Sociedad "La Riqueza de Magallanes" y Sociedad Chilena de Lanas y Graserías, en las que no obstante la nacionalización el mayor accionista en cada una de ellas pasó a serlo la casa británica Duncan Fox. Cumplido ese paso, la segunda sin mayor demora vendió su activo y pasivo a la primera, entidad que -evidentemente siguiendo un plan previamente diseñado- fue adquirida por la Sociedad Explotadora de Tierra del Fuego a principios de 1906.

Con ello todos los campos que una vez habían sido otorgados al pionero fundador quedaron en manos de lo que fuera su inspirada creación. Todo, en cierto modo, había vuelto al mismo saco.

Pero la última fusión trajo consigo un apreciado "regalo" pues "La Riqueza de Magallanes" había hecho otro tanto a comienzos de 1906 con la Sociedad Ganadera Ponsonby y Ultima Esperanza que, a su vez había devenido el año anterior cesionaria del grupo empresarial de Santiago, Fuenzalida, Rodolphy y Cía. que a su tiempo (1904) había adquirido los derechos de concesión sobre 600.000 hectáreas de terrenos situados en la zona marginal del ecúmene magallánico, principalmente sobre la isla Riesco y la zona continental situada al occidente de la comarca de Río Verde, entre el mar de Skyring y el paralelo $52^{\circ}$ (frontera con la República Argentina), y que se extendía hasta el sector noroccidental de la península Muñoz Gamero. Esa gran extensión, amén de geográficamente marginal, era un territorio casi desconocido en su totalidad por sus características fisiográficas y ambientales que lo hacían por entonces poco accesible. De su extensa superficie, la Sociedad Explotadora aprovecharía únicamente los terrenos de la zona nororiental de la isla Riesco. Para lo cual se crearía hacia 1907-08 la "Sección" o "Estancia Isla Riesco".

\section{La inteligente negociación de 1910}

Como resultado de los remates de terrenos fiscales entre 1903 y 1906, la gran beneficiaria de los mismos fue la Sociedad Ganadera de Magallanes, una entidad anónima constituida en 1903 con el exclusivo objeto de participar en las subastas. Entre sus organizadores principales se contaron Ramón Serrano Montaner y Cruz Daniel Ramírez que habían sido amigos de Nogueira y, como tales, partícipes en la creación de la Sociedad Explotadora de Tierra del Fuego, de la que acabaron por desvincularse al enemistarse con los hermanos Mauricio y Sara Braun. Hubo así en esta nueva empresa una suerte de ánimo de desquite con éstos (y con aquélla), pues se pretendía hacer de la nueva entidad una rival económica de la Explotadora, pero asimismo un interés de especulación con el valor de los terrenos dado el auge de la crianza ganadera como factor de rápida riqueza.

Así entonces, y resumiendo, de las 669.775 hectáreas comprendidas en el primer remate (1903), la Sociedad Ganadera de Magallanes se quedó con 220.844 hectáreas; en el segundo, realizado el mismo año, de 257.246 hectáreas en subasta, la Ganadera obtuvo 62.440 hectáreas. En 1905 y 1906 tuvieron ocurrencia los dos últimos remates de tierras fiscales, donde la misma compañía consiguió hacerse con otras 32.160 hectáreas. En total 351.846 hectáreas de campos de pastoreo de la mejor calidad ${ }^{17}$, patrimonio más que suficiente para acreditar la jerarquía económica y empresarial que anhelaba la Sociedad Ganadera de Magallanes.

Así las cosas, con gran reserva hacia fines de 1906 se iniciaron los primeros contactos con miras a la fusión entre la Explotadora y la Ganadera, pero el asunto se abordó seriamente recién a partir de 1909. La iniciativa correspondió a Alejandro Bezanilla Silva, un accionista de la primera, quien tuvo el asentimiento de Peter Mc Clelland. La negociación se llevo con el máximo sigilo para no tener perturbaciones internas ni externas. Preocupaba en especial al directorio de la Explotadora la imagen pública de la Sociedad tras el vapuleo recibido de la opinión popular una vez divulgadas las adquisiciones de tierras en Ultima Esperanza y la compra del activo y pasivo de "La Riqueza de Magallanes". La comunidad regional, en especial el sector ilustrado de la misma, y la prensa, antilatifundistas y prosubdivisionistas en materia de tierras fiscales, veían con temor el crecimiento de semejante imperio empresarial cuyas miras parecían puestas en la totalidad de las tierras pastoriles de Magallanes.

17 Esta cifra variaría levemente a la baja con la remensura posterior de los campos adquiridos. 
Cuando la marcha de las negociaciones hacían prever un acuerdo y luego de la avaluación del activo de la Ganadera realizado por peritos contratados por la Explotadora, su directorio estuvo conforme con la adquisición de aquella entidad considerando, a) la oportunidad excepcional de adquirir un considerable dominio fundiario -tierras inmejorables para la ganadería y bien ubicadas-, sin temor a la competencia de terceros; b) que el precio de adquisición era estimado equitativo; c) que la negociación permitía poner término a la situación de incertidumbre que derivaba para la Sociedad de la incógnita acerca de la renovación del arrendamiento en 1913; y d) que con la desaparición -absorción en realidad- de la Sociedad Ganadera de Magallanes la Explotadora eliminaba un rival molestoso ${ }^{18}$. Fundado en esta y otras razones y consideraciones el directorio de la Sociedad Explotadora aprobó la adquisición del activo y pasivo de la Ganadera de Magallanes, sobre la base del canje de una acción de aquélla por dos un cuarto de la segunda.

No fue una resolución fácil, con todo, pues hubo que superar objeciones internas -entre ellas la muy importante de Mauricio Braun- y enfrentar el rechazo de la opinión pública un vez que, pese a las reservas, el asunto trascendió. Pero, como escribimos alguna vez, ni los reclamos ni las protestas paralizaron la marcha del audaz negocio. Y así el día 10 de enero de 1910 la Junta de Accionistas de la Sociedad Ganadera de Magallanes aprobó la fusión con la Sociedad Explotadora de Tierra del Fuego según los términos convenidos.

De la manera sucintamente expuesta la Sociedad Explotadora tras una sucesión de jugadas maestras alcanzó a principios de 1910 la cima de su posesión fundiaria, al totalizar virtual y redondamente 3.000.000 de hectáreas entre campos de propiedad, arrendamientos y ocupaciones de facto. ¡Eso se llama dominio!

Otras adquisiciones menores realizadas por ese mismo tiempo, principalmente en el suelo argentino de Santa Cruz, elevaron la propiedad fundiaria de la Sociedad Explotadora a 930.444 hectáreas. Para la explotación pastoril de los nuevos campos agregados

18 Mayores antecedentes sobre la materia pueden hallarse en nuestro trabajo "Exploraciones y colonización en la Región Central Magallánica 1853-1920" (Anales del Instituto de la Patagonia, volumen 9, págs. 5-42, Punta Arenas, 1978). a su dominio se crearon dos unidades operativas en suelo chileno, las estancias "Oazy Harbour" (o "Gringos Duros") y "Punta Delgada"; y otras dos en el argentino, las estancias "Sección Oriental" de la estancia "Cerro Castillo" y campos aledaños, y la estancia "Las Vegas", con terrenos adquiridos en la zona centro-sur del territorio de Santa Cruz.

Ese mismo año 1910, en otra expresión de su fuerza económica, la sola dotación de ovinos de esquila de la Explotadora superaba largo el millón de cabezas, con una producción cualificada de lana que se empinaba por sobre los nueve millones de libras (9.212.495).

\section{TECNOLOGÍA DE EXPLOTACIÓN Y PRODUCCIÓN ECONÓMICA}

Es bien sabido que la introducción de ovinos en Magallanes para su crianza extensiva vino de la mano con la modalidad tecnológica para realizarla de manera eficiente, pues una y otra formas eran desconocidas en Chile. Procediendo la masa animal fundadora de la actividad de las islas Falkland (Malvinas), fue cosa natural que también se contratara allí el personal para su cuidado y manejo. Debe recordarse que en esa posesión británica la ovejería se había desarrollado exitosamente desde los años de 1840 y para ello el concurso de pastores -ovejeros- británicos, especialmente escoceses, había sido fundamental.

De ese modo toda la mano de obra requerida inicialmente en Magallanes que suponía algún conocimiento o experticia en la materia estuvo formada en su abrumadora mayoría por súbditos británicos y totalmente en lo referido a los niveles más calificados (administración y capatacería). Estos, si no estuvieron entre los inmigrantes que llegaban en abundancia a Punta Arenas en la época, sí integraron el contingente seleccionado menor que fue expresamente contratado para servir como ovejeros por un tiempo determinado, cumplido el cual fue común el quedarse en Magallanes como trabajadores libres y encontrar de inmediato ocupación en las zonas rurales.

El caso de la Sociedad Explotadora, en tanto que gran empleadora para poner en marcha su actividad económica rural, encaja cabalmente en el esquema descrito en lo que se refiere al tiempo inicial, cuando había que aprovechar lo que estuviera 
a mano. Pero luego, adelantando el tiempo y en la medida que la explotación ganadera se extendía y se hacía más compleja, se inició y llevó adelante un cada vez más riguroso proceso selectivo de personal hasta llegar a tener, prácticamente, el mejor según niveles de responsabilidad.

La calidad de la mano de obra utilizada conformaría así la primera exigencia y, a la vez, cualidad caracterizadora de la nueva empresa. En ello importaban los conocimientos sobre la actividad rural y la crianza ovejera en especial, y la capacidad de trabajo; pero lo esencial sería la subordinación y obediencia, la responsabilidad en la ejecución de las tareas, la honestidad, el interés por aprender y el hacer bien las cosas, siempre. Para ello se pagaba lo justo dentro de los estándares de la actividad y si el trabajador era diligente la ocupación se mantenía indefinidamente, porque a la empresa le convenía conservar a la mejor gente.

Con los años se valorizó especialmente la experiencia acumulada. Ello se refería tanto al manejo de ganado como al conocimiento del campo magallánico, lo que se adquiría a través del tiempo mediante la observación en repetidos recorridos por el terreno en diferentes épocas del año, hábito y práctica que informaban sobre la disponibilidad y variedad de recursos tales como pasturas y aguadas, características topográficas, reparos del viento y noción sobre la variabilidad del clima, particularmente en la época invernal, en fin. Un buen ovejero debía llegar a ser algo así como un buen marinero, cada uno en su elemento, "leyendo" en el aire los cambios favorables o desfavorables que anunciaba el ambiente, dominándolo cada vez mejor. Esto, por cierto, valía igualmente para capataces y administradores. Eso hacía del trabajador un operario muy cotizado porque aseguraba a la compañía un buen servicio cuyo rédito se tenía en los rendimientos anuales de la explotación. Era por tanto un elemento clave en la producción al punto que su labor debió ser más apreciada que otras especialidades operativas.

Ello no significaba minusvalorar otros oficios rurales como los del alambrado, el cuidado de molinos de agua, el amanse de caballos, la cocina, etc. $y$, de acuerdo con la tradición, la administración procuró que los bien capacitados y más habilosos se especializaran en una faena determinada para rendir el máximo de su capacidad. Todo apuntaba al fin al mejor trabajo de conjunto.
En resumen, la crianza ovina en su sencillez operativa se daba para que el conocimiento enriquecido por la experiencia y no obstante la repitencia rutinaria, permitiera conseguir el mejor nivel productivo y, una vez alcanzado, mantenerlo indefinidamente. Formar y conservar el capital humano parece algo obvio en toda empresa económica, sin embargo de que en la realidad no siempre acontece, pero en el historial de la Sociedad Explotadora fue una característica temprana y que, ciertamente, la destaca para la historia.

Si los trabajadores importaban, igualmente lo fue el que hábilmente dirigida como estuvo la Sociedad, se pusiera a su disposición todos los elementos (equipos, máquinas, herramientas, vehículos y otros diferentes elementos) que la tecnología industrial en incesante adelanto colocaba en el mercado, como cosa necesaria para hacer que las labores fueran más eficaces y los resultados los más eficientes y mejores posibles de obtener. Para ello la Administración General a través de sus agentes en el Reino Unido estuvo oportuna y suficientemente informada sobre toda novedad o innovación tecnológica que fuera atingente a la actividad criadora primordial de la Sociedad y sus derivados. Y en esto, va de suyo, la Explotadora no se ahorró recursos.

El sociólogo Joaquín Bascopé en reciente estudio ha abordado, entre otros aspectos, esa característica empresarial que califica de "tecnologización", describiéndola con acierto: En efecto, la ganadería ovina devino un laboratorio donde las fábricas de fierro y de acero británicas, así como el know how de sus técnicos, pudieron realizar una experiencia inédita. Desde los clavos hasta los tractores, desde el alambre hasta las prensadoras de lana, desde las planchas de zinc hasta los automóviles, el "complejo estanciero" albergaba los avances recientes de la industria europea y los ponía al servicio de la producción ovejera ${ }^{19}$.

Claro es que obtenido el nivel de eficiencia que la actividad requería, el proceso de tecnologización fue desacelerándose en la medida que el equipamiento de que se disponía fue satisfaciendo los requerimientos productivos, para limitarse a lo largo del tiempo a las solas adquisiciones de reemplazo o de renovación de

19 Pasajeros del poder propietario. La Sociedad Explotadora de Tierra del Fuego y la biopolítica estanciera (1890-1920). Magallania, 36(2), Punta Arenas, 2008, pág. 22. 
material, configurándose una suerte de inmovilidad tecnológica. Inclusive ello se dio cuando luego de los siniestros que destruyeron algunas instalaciones industriales de curtiembre y lavado de lana en Puerto Bories, no se las reconstruyó ni rehabilitó, circunstancia particular que permite afirmar que se dio un retroceso en tal aspecto productivo. Fue así porque lo que se quería era satisfacer el mejor estándar de calidad productiva en el nivel que lo tenía la propia actividad ganadera en el contexto de la división internacional de la economía, esto es, la producción de carácter primario. En este esquema, concordando con Bascopé, radicaba la clave del éxito económico: altos rendimientos económicos basados en las dimensiones de la explotación ${ }^{20}$, con sólo la necesaria inversión y la innovación tecnológica según conveniencia o necesidad.

La tecnología utilizada, por lo demás, no se limitó al trabajo propiamente productivo, según comúnmente se lo entiende, y se extendió a los servicios de apoyo, campo en el que las comunicaciones personales mediante la telefonía alámbrica pasaron a ser esenciales. Hasta la incorporación de la Corporación de Fomento de la Producción (CORFO) en la actividad económica magallánica a principios de los años de 1940 que, como en otros aspectos introdujo la tecnología más moderna disponible y de la que se hizo un eficiente uso, ninguna empresa productiva haría tan buen empleo de la telefonía como factor de organización y de apoyo productivo.

Así, como una consecuencia lógica de una planificación seria y una rigurosa aplicación, la actividad productiva matriz, la lana, fue alcanzando las exigencias referidas al rendimiento por animal y de finura de la fibra, (lo que suponía un paciente, laborioso, largo y costoso trabajo de selección de ovinos), con lo que fue posible tener un nivel de calidad según los exigentes estándares requeridos por el mercado lanero internacional y cimentar así tempranamente una fama, a modo de marca, "lanas Punta" (por Punta Arenas el puerto de embarque del producto para la exportación), algo equivalente a lo que hoy en día se entiende por "denominación de origen" para calificar un estándar acreditado y reconocido.

El siguiente cuadro ilustra acerca de la evolución registrada en lo tocante al rendimiento de lana

20 Id. por animal, de acuerdo con los antecedentes que han podido compulsarse:

Tabla 2 .

\begin{tabular}{|c|c|c|c|}
\hline Año & $\begin{array}{c}\text { Animales } \\
\text { esquilados }\end{array}$ & Libras de lana & $\begin{array}{c}\text { Promedios por } \\
\text { animal }\end{array}$ \\
\hline 1906 & 582.191 & 3.993 .648 & $6,87 \mathrm{lbs}$. \\
\hline 1910 & 1.173 .125 & 9.281 .629 & $7,91 \mathrm{lbs}$. \\
\hline 1915 & 1.163 .968 & 8.793 .365 & $7,55 \mathrm{lbs}$. \\
\hline 1920 & 1.127 .665 & 9.115 .442 & $8,08 \mathrm{lbs}$. \\
\hline 1925 & 1.213 .168 & 10.027 .105 & $8,26 \mathrm{lbs}$. \\
\hline 1935 & 1.293 .873 & 11.242 .143 & $8,69 \mathrm{lbs}$. \\
\hline 1940 & 1.125 .133 & 11.177 .882 & $9,88 \mathrm{lbs}$. \\
\hline 1945 & 1.113 .288 & 11.482 .694 & $10,31 \mathrm{lbs}$. \\
\hline 1950 & 1.098 .600 & 10.831 .482 & $9,86 \mathrm{lbs}$. \\
\hline 1955 & 1.020 .274 & 9.310 .889 & $9,13 \mathrm{lbs}$. \\
\hline 1959 & 843.423 & 7.882 .857 & $10,44 \mathrm{lbs}$. \\
\hline 1965 & 874.530 & 8.594 .393 & $11,52 \mathrm{lbs}$. \\
\hline 1968 & 1.039 .001 & 10.003 .322 & $11,31 \mathrm{lbs}$. \\
\hline
\end{tabular}

Lo notable de este resultado favorable en el tiempo es que el mismo se obtuvo gracias a un trabajo consciente y sostenido (no obstante las situaciones climáticas imprevisibles), primero sobre una cantidad de ovinos de esquila prácticamente invariable entre 1910 y 1955 (en promedio 1.100 .000 animales) que se mantuvo no obstante la reducción de los campos de pastoreo por las restituciones de parte de los mismos al Fisco (1916, 1924, 1938); y segundo, porque tras la disminución obligada que debió hacerse en la dotación ovejera a contar de 1958, el rendimiento por cabeza no sólo se mantuvo sino que creció hasta virtualmente doblar en 1968 la cifra registrada sesenta años antes.

De esa manera, la Explotadora llegó a ser un modelo referencial de buen trabajo productivo para la ganadería ovina patagónica, que el resto del empresariado grande o mediano se empeñaría en seguir.

Por fin, en el aspecto operativo de que se trata es evidente que el mismo en su desarrollo y resultado históricos pudo darse en la situación del latifundio imperante, del que la Sociedad Explotadora de Tierra del Fuego fue en cierto modo causa y efecto. Únicamente sobre un dominio vastísimo como el suyo, en sentido amplio (propiedad y arrendamiento) podía erigirse un poder económico de la envergadura que se le conoció históricamente a esa compañía. Y su existencia y evolución fueron a su tiempo la prueba tangible del éxito del sistema, más allá de su mayoritario rechazo social. Sin latifundio 
la historia empresarial de que se trata habría sido diferente. El uso eficiente del mismo en cuanto significaba poder de control y de gestión eficaces y omnímodos (territorio, circulación, autoridad factual, disponibilidad de recursos), no se habría dado como se dio sin el sistema latifundiario, además de su indiscutible poder de influencia sobre la sociedad e incluso sobre la administración del Estado (sobre algunos de sus agentes a lo menos). Por ello, y no sin razón, alguna vez se dijo en Punta Arenas que más poder real había en la esquina de las calles Roca y Lautaro Navarro (sede de la Administración General de la Sociedad Explotadora) que en la plaza Muñoz Gamero (donde se situaba la Intendencia, esto es la autoridad política territorial).

\section{LA GENTE DE LA EXPLOTADORA}

Desde un principio y prácticamente sin variación a lo largo de toda su vigencia la "Compañía" -como se la nombraría habitualmente entre su personal-estableció un ordenamiento jerárquico estricto en su accionar operativo, situación especialmente notoria en el ámbito rural, sector donde evidentemente se desarrollaba la actividad fundamental de la empresa. Tal ordenamiento condicionó las relaciones y la vida laborales estableciéndose de esa manera un patrón caracterizador singular, y como tal irrepetido, en la historia socio-económica de Magallanes.

En tal contexto, desde un comienzo se impuso igualmente una diferencia entre sectores, esto es, la parte directiva y administrativa superior de la Sociedad -la Gerencia General y la Administración General-y la parte operativa técnica, exclusiva del ámbito rural. Aquélla, propiamente la dirección general estuvo radicada en Punta Arenas por algo más de una década tras la fundación y puesta en marcha de las actividades, y luego, a partir de 1905 , se produjo una separación con el establecimiento de la Gerencia General en Valparaíso, en tanto que la Administración General se mantuvo en Punta Arenas. Cada uno de, estos sectores generó su propia planta funcionaria. La primera se formó sobre la base de personal de capacidad y confianza vinculado a redes políticas y sociales (a la propiedad accionaria) de Valparaíso y Viña del Mar principalmente y que, para los efectos de este artículo, es una entidad de interés secundario en tanto cuanto quienes formaron parte de ella a lo largo del tiempo, siendo como fueron todos empleados de la compañía, se sintieron distintos y hasta cierto punto ajenos al mayor contingente laboral de la empresa radicado en Magallanes.

La segunda en cambio mantendría para la historia la más plena y apropiada identificación con los fundamentos y la razón de ser de la Sociedad Explotadora de Tierra del Fuego, en tanto que operaría sobre el territorio natural de la actividad criadora y productiva. En ella, otra vez, cabe subdividir entre la Administración General con su compleja planta laboral, radicada en Punta Arenas, y los distintos establecimientos de producción dispersos en el ámbito rural (estancias y el Frigorífico Bories). Cabe destacar que durante la mayor parte de la vigencia de la Sociedad (hasta 1960) los niveles jerárquicos superiores (administradores y subadministradores generales) fueron llenados únicamente por los empleados (jefes) que habían ganado mérito por su competencia técnica y buen y leal servicio a lo largo de toda una vida ${ }^{21,22}$. Cada una de las divisiones mencionadas tuvo sus propias jerarquías de mando y responsabilidad y originó sendas carreras administrativas autónomas. Exceptuados los casos de las más altas jefaturas señaladas, por lo común no hubo traspasos o intercambios intersectoriales.

Ingresar a la Sociedad Explotadora fue por años (para un par de generaciones a lo menos) una suerte de meta laboral, especialmente en una época en que la vida escolar en Magallanes culminaba prácticamente para la generalidad de los jóvenes con el primer ciclo de humanidades y en que la prosecución de los estudios en las universidades estaba determinada por la situación económica de la familia. De ahí los empeños y recomendaciones para ingresar a tan interesante empleo, en

21 Así, entre 1905 y 1961 ejercieron el cargo de Administrador General Alexander Cameron (1905-1915), Thomas Burbury (1915-23), Leslie Greer (1923-1949), K. Carnegie Ross (1950-52), E.J. Piggot (1953-61) y John Gibbs(...) todos antiguos administradores de estancias.

22 La excepción que confirma la regla la conformó Guillermo Santa Cruz quien durante algunos años de la década de 1950 fue administrador del Frigorífico Bories, puesto que sin duda consiguió por su relación familiar con Tom P. Jones, cónsul de Gran Bretaña en Magallanes, de quien era yerno. Se trató de una doble excepción en realidad, una, por la circunstancia antedicha, y otra por su nacionalidad chilena, aunque para entonces esta condición comenzó a ser más frecuente si bien referida a chilenos de ascendencia británica. 


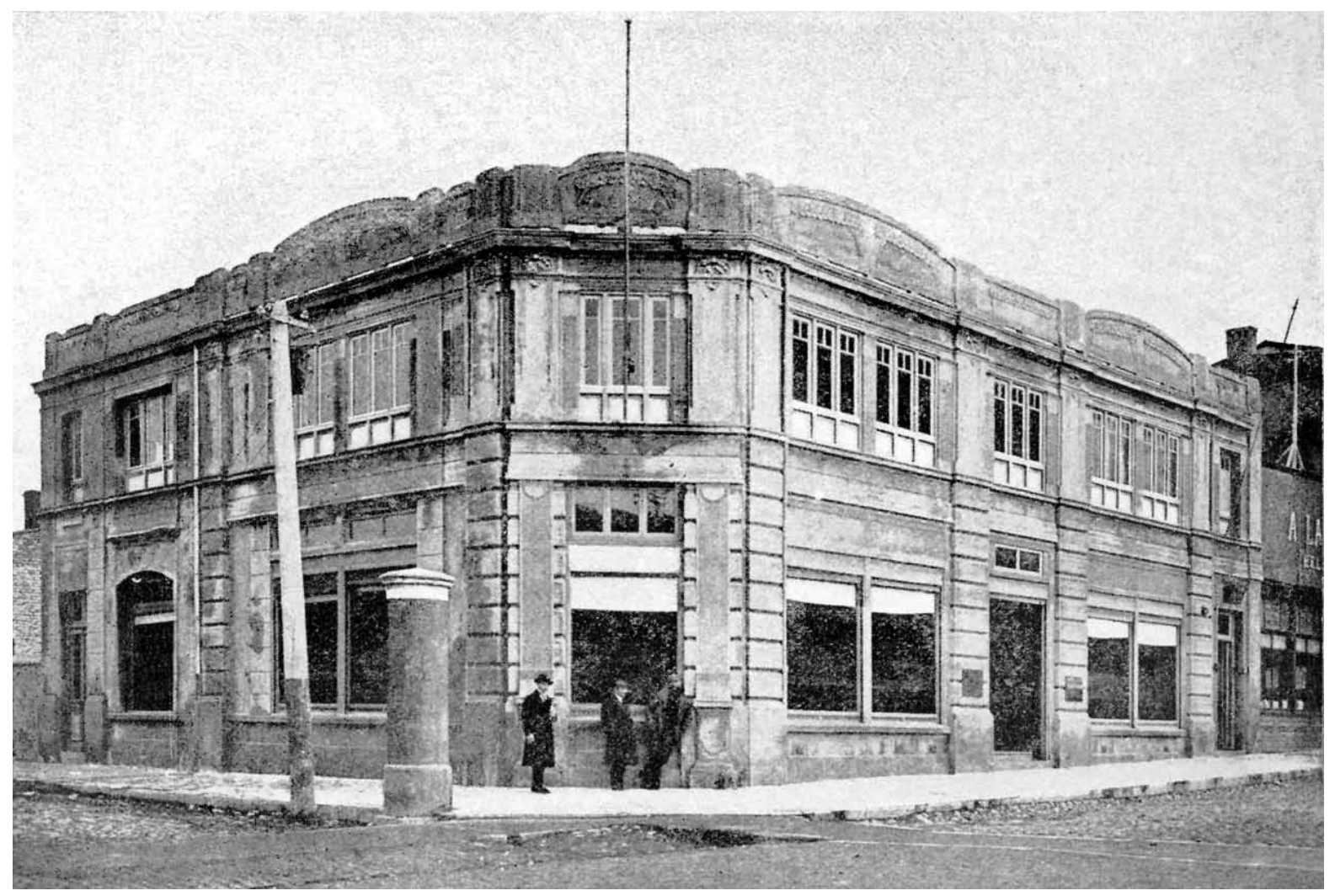

Fig. 1. Edificio de la Administración General de la Sociedad Explotadora de Tierra del Fuego (Fotografía 1920).
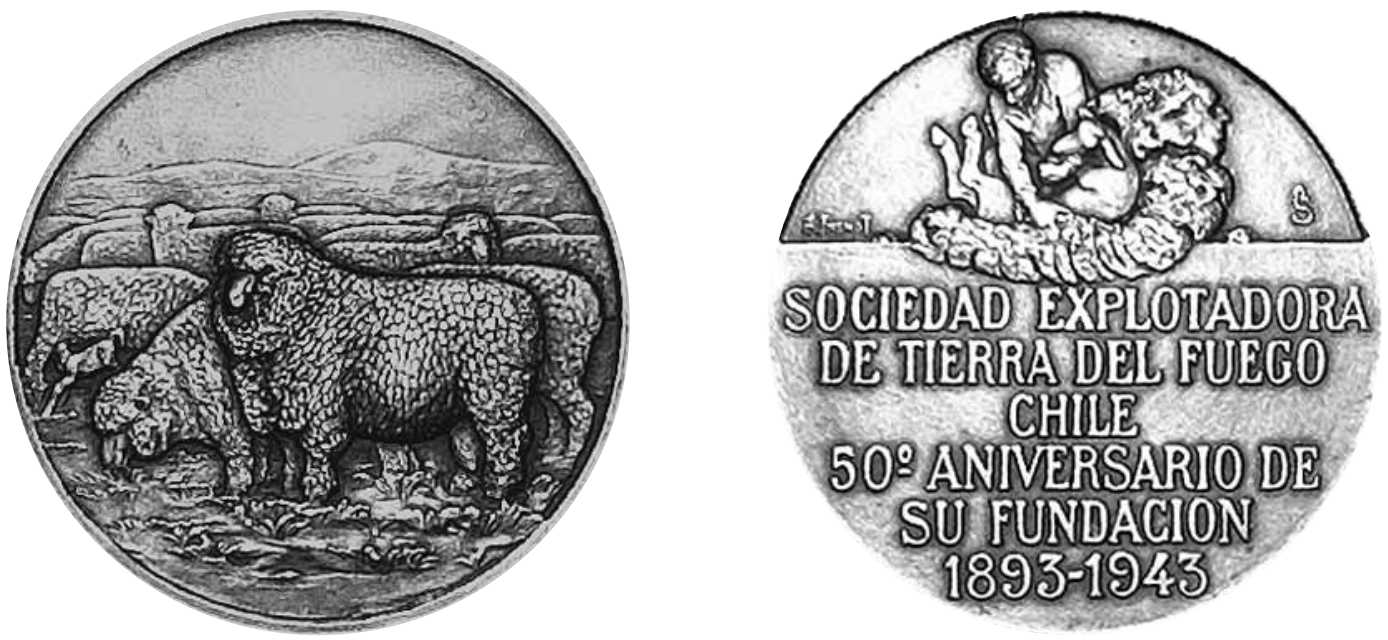

Fig.2. Medalla Conmemorativa del cincuentenario de la Sociedad Explotadora de Tierra del Fuego. 
un territorio donde la oferta no abundaba y la que se daba estaba definida desde largo tiempo por la invariabilidad de posibilidades. $Y$ tal posibilidad de ingresar a la entidad más importante, fuerte y prestigiada lo era por la seguridad que brindaba en cuanto a la permanencia en el trabajo, siempre que se cumpliera con las estrictas normas internas, y por las remuneraciones que estaban situadas en un nivel razonable para su tiempo, situación que compartían otras contadas empresas empleadoras tales como Braun \& Blanchard, la Sociedad Anónima y Ganadera Menéndez Behety y el Banco de Londres y América del Sud Ltdo. ${ }^{23}$. Si el postulante era de origen británico de partida tenía una ventaja que, con alguna otra condición o exigencia, le aseguraba la mejor opción para la contratación.

Tocante al trabajo propiamente administrativo, que se compartía entre las oficinas de Valparaíso, Punta Arenas y las de los establecimientos rurales, como en lo correspondiente a las tareas técnicoganaderas realizadas únicamente en las estancias, su desarrollo dio origen a carreras funcionarias a cuyos niveles por lo común se accedía por mérito y antigüedad. Quienes integraban las correspondientes plantas tenían la condición de empleados particulares con los derechos y beneficios establecidos para los mismos a partir de la legislación social de 1924-25.

El personal inferior de la compañía, esto es, el que realizaba trabajos preferentemente manuales -los obreros- conformaba el grueso de la dotación laboral de la Sociedad Explotadora de Tierra del Fuego. En un principio las diferentes faenas propias de la explotación ganadera fueron determinando las especialidades requeridas, circunstancia que corriendo el tiempo, cuando la actividad se generalizó, permitió contar con conocimientos y experiencia que facilitaban el ingreso (ovejero, esquilador, campañista, carretero, mecánico, carpintero, cocinero, alambrador, etc.); para quien carecía de algún conocimiento de la vida del campo o lo poseía en grado estimado insuficiente sólo quedaba la posibilidad de iniciarse como peón para todo servicio. Al revés de lo que ocurría entre los empleados administrativos o técnicos, en este estamento la permanencia en el puesto estaba determinada por las necesidades de

23 Los sueldos y los salarios más altos comenzaron a ser conocidos en Magallanes tras la instalación de la CORFO para el desarrollo de las exploraciones petroleras (1942). la compañía que, a su vez, se ajustaban al curso del año ganadero. Así, había "faeneros o trabajadores de temporada" (situación que admitía subdivisión entre quienes desempeñaban labores específicas con término conocido, y los que de algún modo podían continuar en servicio) y "los de año redondo". Entre estos, con permanencia indefinida, se daba la posibilidad de una carrera laboral limitada que permitía alcanzar el puesto de capataz (excepcionalmente la responsabilidad de "capataz de sección" para los más meritorios) o la jefatura de un taller.

El desempeño en la función (conducta, habilidad para la misma, rendimiento) garantizaba tanto la recontratación en la categoría de los temporales (o temporeros), como la permanencia en los de año redondo. Para unos y otros la seguridad del puesto era el mayor anhelo. No sólo por la duración del empleo del que dependía la existencia propia y la de familiares, si los había, sino además por el goce de algunas ventajas que los trabajadores fueron consiguiendo con los años a través de sus convenios colectivos, que en el caso particular de la Explotadora se refería a la provisión regular de carne para las familias de sus obreros temporales durante el tiempo en que los mismos estando desvinculados del servicio aguardaban la recontratación. Esta modalidad se denominaba "crédito de invierno" y el valor correspondiente, siempre de muy bajo monto, se descontaba de los futuros haberes.

[...] al terminar la faena al trabajador se le seguía suministrando sus raciones de carne y víveres, lo cual lógicamente se pagaba en la próxima temporada al empezar nuevamente la faena y eso hoy en día ninguna empresa lo hace. ${ }^{24}$

Los trabajadores que se desempeñaban en temporada tenían la garantía que la empresa les vendía víveres y carne y lo pagaban en la próxima faena. En Castillo se vendía ropa, zapatos, todo a precio de costo. ${ }^{25}$

24 Declaración del señor Félix Dillems en entrevista hecha por Guillermo Ruiz Santana (alumno de la carrera de Historia en la Universidad de Magallanes), por encargo del autor, durante el invierno de 2010. El señor Dillems trabajó en el área administrativa contable de la S.E.T.F. entre 1942 y 1965. Una información semejante fue entregada por otro entrevistado, el señor Ernesto Pérez Castañón, antiguo maquinista del ferrocarril de Puerto Bories.

25 Declaración del señor Ricardo Livingston Bianchi, igualmente antiguo empleado de la Sociedad que alcanzó el puesto de administrador de estancia, al mismo entrevistado. 
Los trabajadores de la Sociedad Explotadora estaban asegurados. Todos querían trabajar en la Sociedad Explotadora ${ }^{26}$.

Pero si la Sociedad así favorecía a sus servidores, también les exigía y mucho. La disciplina era estricta y el trabajo debía hacerse bien; por lo tanto el empleo se cuidaba [...] había mucha gente esperando por un puesto (Trincado) y quien cumplía como se debía tenia la garantía de la ocupación de por vida.

[...] la Compañía tenía principios que conservaba a sus empleados lo que no pasa hoy en día con las empresas [...] En cambio la Ganadera [SETF] no, un empleado pasaba años, mucha gente jubiló en la empresa y a los buenos se los mantenía bajo cualquier punto de vista. Otra cosa es que en la Sociedad trabajaba la familia entera, el padre y si este fallecía quedaba el hijo o sino el cuñado o el yerno; además se formó mucha relación social y familiar gracias a la empresa (Dillems). Esta circunstancia de harto común ocurrencia parece haberse dado particularmente entre la gente de Última Esperanza, distrito territorial para el que la actividad de la Explotadora fue determinante en su evolución económica y social durante dos terceras partes del siglo XX.

En la vida rural de la Sociedad Explotadora por otra parte, la comunidad de trabajo se conformó desde sus inicios con un apreciable contingente extranjero -abrumadoramente británico-y un componente chileno -que devendría chilote, también abrumadoramente-, que en lo referido a porcentajes de participación registraría una diferente relación que mucho antes del final empresarial llegaría a ser inversamente proporcional a la del comienzo: de ser mayoritariamente extranjera y minoritariamente nacional, a lo opuesto.

Los extranjeros -los británicos, o "gringos" en el lenguaje popular-, gozaron durante décadas de las ventajas que su origen étnico les brindaba, lo que se manifestó en el trato y comodidades que recibían, aunque tal situación se fue morigerando con el paso de los años. Fue una tradición que se

26 Roberto Trincado, ex-administrador de estancias, en El perro ovejero magallánico: Testimonio de reconstrucción histórica, trabajo de seminario de Alvaro Fuenzalida, Instituto de Historia, Facultad de Historia , Geografía y Ciencias Políticas, Pontificia Universidad Católica de Chile (Santiago, 2005). estableció y generalizó en toda la actividad ganadera por el hecho de la procedencia de la misma y en la Explotadora, por cierto, la misma cobró más fuerza y vigencia. Hubo de transcurrir mucho tiempo, prácticamente hasta pasado 1950, para que los chilenos lograran acceder a ese estatus preferente, pero entre tanto la diferencia en la materia fue notoria, aunque aceptada comúnmente como algo normal no sólo en cuanto se refería al trato y comodidades, sino a las exigencias del trabajo.

[...] yo siempre tuve que trabajar el doble y creo que eso le pasaba a todos los chilenos que estábamos allá; teníamos que trabajar el doble y ser más que ellos [los británicos]; algunos lo hicimos, otros no pudieron. Los gringos nos ponían las tareas difíciles a los chilenos, recordaría en su retiro Roberto Trincado que inició vida laboral en la S.E.T.F. como cadete en 1953 y la concluyó brillantemente como administrador de estancia ${ }^{27}$.

Las diferencias si se dieron entre nacionales y extranjeros, lo fueron igualmente en el interior de ambas comunidades por razón de la responsabilidad laboral o posición funcionaria que se tenía, como la hubo y notoria entre los empleados y los obreros, especialmente en lo referido a habitaciones, alimentación, comodidades y servicios.

Si bien históricamente se registró una preocupación preferente por la calidad de vida que se daba a los empleados de los niveles jerárquicos superiores, también la hubo aunque en menor grado respecto del trato a los trabajadores comunes especialmente en lo tocante a alojamiento y comodidades inherentes, pero, en este caso, esta preocupación fue más el fruto del reclamo laboral sostenido que de una conciencia patronal acerca de la bondad de la medida. A veces, incluso, por sobre consideraciones humanitarias pudieron darse circunstancias de conveniencia política o de oportunidad ante situaciones de interés directo de la Sociedad. Un recorrido por las menciones de los sucesivos balances sociales revela el interés por brindar comodidades de habitación (edificación de viviendas) para sus trabajadores, en particular para quienes se desempeñaban como "puesteros" y, por lo tanto, debían vivir aislados en los campos, circunstancia que permitió incorporar a las familias de los que eran casados en la medida que se dispuso de casas decentes y cómodas, lo que se

27 Id. op. cit., pág. 60. 
dio una vez que la Administración General autorizó la presencia de familias en los niveles inferiores de sus trabajadores, hecho que se generalizó en 1940. Beneficios anexos a las viviendas fueron los de suministro de leña para la calefacción, de carne y leche para la alimentación y, según el tipo de empleo, el servicio personal para determinados efectos. Pero, en general, en este importante aspecto de la vida laboral en el ámbito rural no siempre fue así y la situación fue modificándose desde la insensibilidad del comienzo (salvas las excepciones mencionadas) a la progresiva apertura según los principios que la modernidad en lo social fue imponiendo en el mundo occidental tras la Primera Guerra Mundial y la Revolución Rusa, lo que contribuyó a morigerar o aun a superar la vigencia del capitalismo industrial "duro" anterior a esa conflagración.

En lo que se trata, en un comienzo el sistema de vida laboral en los establecimientos de la Explotadora era azás precario y hasta miserable, salvo el caso de las jerarquías técnicas que siempre recibieron el mejor trato, y no fue sino después de reiterados reclamos y denuncias (especialmente a contar de la creación de la Federación Obrera de Magallanes en 1911) que la situación comenzó a variar. En materia de habitaciones obreras, por ejemplo antes de que existiera la Federación, en el campo sobre todo, eran pésimas; en Caleta Josefina, estancia de la Sociedad Explotadora, en Tierra del Fuego, las habitaciones que se dedicaban a los trabajadores eran los establos, en que se guardaban los caballos durante el invierno; sucias, mal olientes, llenas de estiércol $i$ aberturas, por donde se colaba el aire que, al mismo tiempo de llevarse muchas vidas, esparcía la miseria en muchos hogares de Chiloé $i$ del Territorio; el patio que rodeaba las casas permanecía siempre lleno de lodo i desperdicios de la comida, que en el verano fermentaban con el calor produciendo una atmósfera irrespirable; los comedores eran galpones con tablas mal unidas como mesas, las que estaban siempre cubiertas de una gruesa capa de mugre; el servicio de mesa era de lata, i las tazas $i$ las copas eran reemplazados por tarros vacíos de conserva.

La vida en tal condición en Magallanes, es imposible; el clima reclama cierto confort i el aislamiento hace imprescindible, a más de aquél, la existencia de habitaciones especiales, con buena calefacción, para lectura i el esparcimiento después de las horas de trabajo, ya que el tiempo impide, por lo común, toda distracción al aire libre.

En la actualidad la misma estancia nombrada posee excelentes y cómodos edificios para habitaciones i comedores de trabajadores, i todo ello se debe a la acción benéfica de la Federación.

Lo que ha conseguido en el sentido indicado, también lo ha obtenido en materia de alimentación, jornada de trabajo, etc., i todo ello sin que haya sufrido jamás detrimento alguno ni la propiedad de los estancieros, ni menos hayan entorpecido estas concesiones el proceso del Territorio ${ }^{28}$.

Aunque así escribía el abogado Manuel Chaparro Ruminot hacia 1916-17, la verdad es que todavía años después la situación de que se trata distaba de ser satisfactoria, según lo comprobaría personalmente el capitán de ejército Arturo Fuentes Rabé en lo que sería un memorable recorrido por Tierra del Fuego en $1921^{29}$. Tocante a la alimentación la misma fue abundante desde un comienzo, si bien no muy variada (con predominio de carne y papas) y en este aspecto pocas veces hubo reclamos y cuando se dieron fueron respecto de la variedad y nunca sobre la cantidad. El mismo Fuentes Rabé entrega antecedentes sobre la alimentación de los obreros en la estancia "Caleta Josefina" en esa época, por lejos superior a la de otros trabajadores del centro y norte de Chile entonces y aun en tiempo posterior.

Y así se pasó de la indecencia a la decencia, de la indignidad a la dignidad en el trato que la gente de las estancias merecía. Pero fue un proceso de largo desarrollo que al fin satisfizo a todos ${ }^{30}$. Con sus bemoles, fue un proceso en el que muchas veces la Sociedad Explotadora impuso las normas en el sector productivo agropecuario que no demoraron en ser adoptadas por la mayoría del empresariado.

En cuanto a las remuneraciones, en lo que decía con las correspondientes a los empleados, cualquiera fuera su posición jerárquica, la norma habitual fue la

28 Manuel Chaparro Ruminot, Estudio Económico-Administrativo- Social del Territorio de Magallanes (Santiago, 1917), págs. 94 y 95.

29 Arturo Fuentes Rabé, Tierra del Fuego (Valdivia, 1923), tomo II, pág. 25

30 Tan largo como que el uso de colchones para dormir en remplazo de los cueros de ovejas recién se impuso hacia el medio siglo XX y ello no sólo en el caso de la Explotadora cabe puntualizar, sino en el de la generalidad de las actividades ovejeras en la Patagonia a uno y otro lado de la frontera internacional 
de ceñirse a lo convenido entre la empleadora y el trabajador, aspecto en el que el nivel de referencia estaba dado por los salarios o sueldos pagados en la generalidad de las empresas(para lo que solía darse concierto entre ellas), respetándose las normativas legales de protección laboral una vez que las mismas se establecieron a contar de los años de 1920. En lo que se refería a los obreros fue diferente, pues se pasó desde lo discrecional del comienzo, cuando el empleador fijaba la remuneración y el trabajador simplemente aceptaba si deseaba el empleo, hasta la instauración de los convenios colectivos surgidos a fines de los años de 1910, tras una serie de reclamos $y$ huelgas en que los obreros mostraron su fuerza ante el empresariado rural.

Estos convenios colectivos de trabajo se pactaban anualmente, con antelación a la época de mayor actividad de la ganadería ovina (parición, esquila y demás) y versaban sobre remuneraciones según tipo de tareas y beneficios adicionales referidos a la seguridad de las faenas, la alimentación y el alojamiento entre otros. De lata discusión entre los representantes de las partes patronal y obrera (Sociedad Rural de Magallanes, inicialmente, después la Asociación de Ganaderos de Magallanes -de la que la Sociedad Explotadora de Tierra del Fuego era la principal integrante-, por los patrones, y el Sindicato de Obreros Ganaderos de Magallanes, por los trabajadores), siempre se llegaba a un acuerdo, aunque a veces al cabo de largas e infructuosas negociaciones y, excepcionalmente, de alguna huelga general. En ocasiones también la parte patronal supo usar del soborno para ablandar a algunos dirigentes y facilitar así el acuerdo, cosa de la que la gran masa laboral no estuvo enterada. Pero así funcionaba el sistema de relación obrero-patronal durante la larga época de vigencia del latifundio ganadero.

En la historia empresarial de la Sociedad Explotadora, la convivencia obrero-patronal registró avatares. En un contexto comprensivo habitual de estrictez disciplinaria, trabajo exigente y respeto a la jerarquía por parte de los trabajadores y de comprensión de derechos y buen trato a los que aquellos son acreedores por parte de los agentes patronales (administradores de estancia principalmente), hubo excepciones lamentables como la situación que dio origen a los incidentes sangrientos de enero de 1919 en Puerto Bories y Puerto Natales motivados por la agitación obrerista de la época y el excesivo celo de la autoridad patronal, sobre los que no viene al caso pormenorizar. ${ }^{31}$ Restaurado el orden, la convivencia retornó paulatinamente a la normalidad y no se conocieron a partir de entonces situaciones semejantes, sin embargo de que la discrecionalidad en el manejo operativo por parte de los administradores originó de vez en cuando algún caso de arbitrariedad igualmente excepcional ${ }^{32}$.

Pero, se reitera, en la extensa historia institucional la vigencia de una convivencia razonable fué la norma general, particularmente a contar de 1920. Ello condujo a la larga a la generación de sentimientos recíprocos de aprecio entre la Sociedad y su gente, aquélla valorando la lealtad y la calidad de los servicios laborales -en especial de los trabajadores de origen chilote-, y éstos retribuyendo con afecto y apoyo a su empleadora, sentimientos que corridas cuatro décadas desde el término de la actividad empresarial todavía se mantienen en el recuerdo de antiguos servidores -con la nostalgia de una suerte de época dorada-, más persistentes quizá entre los trabajadores de menor nivel que entre los empleados de alguna jerarquía.

Así, con aspectos de dulce y de agraz, se dio la vida laboral de la Sociedad Explotadora de Tierra del Fuego y acabó por imponerse la aceptación de su existencia como una cosa buena y necesaria para la inmensa mayoría de la gente, en especial entre la población de Última Esperanza, cuyo desarrollo socio-económico estuvo tan ligado a la actividad de esa compañía.

En esta comprensión a nadie sorprendió que los trabajadores de la estancia "Punta Delgada" se opusieran en 1970 a la expropiación de la misma por razón de la aplicación de la Reforma Agraria en Magallanes y eso que su inspiración política era reconocidamente socialista, actitud en que los mismos

31 Al lector interesado en la materia le sugerimos consultar nuestra obra Ultima Esperanza en el tiempo, en especial el capítulo "La vida territorial entre 1910 y 1920".

32 Tal fué él caso investigado por el señor Nelson Álvarez y referido al despido en 1954 de Darío Garay por razón de sus simpatías políticas, manifestadas para el caso en la colocación de un letrero de propaganda en favor del candidato Carlos Ibáñez del Campo para las elecciones presidenciales de 1952 , actitud que le pareció inconveniente al administrador de la estancia "Cerro Castillo", George Saunders ("Un campesino le escribe a Su Excelencia: el desahucio político, una figura amparada por la legislación laboral", trabajo de seminario, carrera de Licenciatura en Historia, Pontificia Universidad Católica de Valparaíso, 2010) 
expresaron un sentimiento que era generalizado entre los obreros rurales. Cuando tal proceso se llevó a cabo en la etapa final del gobierno del Presidente Eduardo Frei Montalva y más todavía cuando la medida se generalizó durante la administración de su sucesor, Salvador Allende, afectando a la totalidad de la propiedad rural latifundiaria, les gustara o no, los trabajadores se resignaron a lo inevitable.

Años después, desaparecida la otrora poderosa entidad, la nostalgia por aquel buen tiempo en el que la Explotadora había reinado en majestad fue cosa de común ocurrencia, de manera particular entre los antiguos obreros y empleados de Ultima Esperanza.

Aquí en Natales, recuerda Félix Dillems, a muchos de los que quedan usted les pregunta qué fue para ellos la Explotadora y ellos le van a decir que fue su vida y que la echan de menos. Tal vez viviendo y estando ahí en otra época había algunos problemas, pero con la perspectiva que dan los años se han dado cuenta de cuánto sirvió la empresa y muchos si fueran más jóvenes y pudieran volver [a trabajar] lo harían. [...] de no haber sido por la Reforma Agraria quizá la empresa hubiera seguido, muchos habrían peleado y dado su voto para que ello ocurriera. Yo he conversado con muchos y recuerdan cuánto se perdió cuando desapareció la Ganadera. El buen recuerdo queda, no sé si en todos, pero en la gran mayoría sí $i^{33,34}$.

No nos cabe duda de que este testimonio responde a un sentimiento colectivo, fruto, se reitera de una comprensión y aceptación recíprocas entre la Explotadora y su gente. Desconocemos si una situación semejante pudo darse entre otros antiguos patrones del sector agrario chileno y su personal y si así sucedió, de cualquier modo debió ser distinto, esto es, que la ligazón anímica entre aquella entidad empresarial y su personal fue única y, como tal, irrepetida.

33 Entrevista citada.

34 Hasta la mitad del siglo XX la Sociedad Explotadora de Tierra del Fuego fue la mayor empleadora de Magallanes, época en que pasó a ser superada por la Empresa Nacional del Petróleo tanto en el número de trabajadores como en la continuidad de los contratos. Como referencia señalamos que en el trienio 1967-69 la misma tuvo un promedio de 2.200 trabajadores entre empleados (208) y obreros (2.000), cantidad esta última de la que la mitad pudo corresponder a la modalidad de temporada y el resto a la de año redondo en lo tocante a contrataciones.

\section{EL DESAFÍO DEL MEDIO SIGLO XX: RENOVARSE O LANGUIDECER.}

\section{Situación en la postguerra mundial}

El período que siguió a la terminación de la Segunda Guerra Mundial (1939-45), aproximadamente un lustro, afectó como bien se sabe el ordenamiento económico de todo el mundo de diversa manera, en particular a los países productores de materias primas o de bajo valor agregado, sector que debió soportar con mayor rigor la situación derivada de la menor demanda y de la baja de precios de los productos, repitiéndose así lo acontecido en la primera postguerra mundial. Entre los afectados estuvo Chile, con mayor propiedad sus regiones productoras ovinas Aysén y Magallanes. En esta, la Sociedad Explotadora de Tierra del Fuego era lejos la mayor productora por lo que la rentabilidad de su actividad se vio igualmente tocada por ese avatar. A ello, además, se sumaron las consecuencias de las siempre imprevisibles contingencias climáticas sud-patagónicas para la crianza ovina, con inviernos y primaveras muy fríos $(1946,1948)$ o épocas de sequía (1952-53) en lo que decía con la menor producción e inclusive con su calidad. Los menores rendimientos económicos tuvieron asimismo un componente negativo debido al creciente costo anual de producción por causa de los aumentos de salarios y sueldos, de los precios de algunos insumos y de otro carácter, como fue la variación del tipo de cambio de la libra esterlina, moneda con la cual se hacían las operaciones comerciales.

Por si faltaba la Sociedad Explotadora de Tierra del Fuego asumió el desafío de la baja obligada de su masa ovina por causa de la devolución de parte de los terrenos fiscales arrendados en la isla grande fueguina, según pasa a verse, con lo que se completa el contexto preocupante dentro del que pasó a desenvolverse la actividad productiva a contar de 1946-50 y por el lapso de veinte años que seguiría a la mitad del siglo XX. Vale decir todo un desafío de proporciones: enfrentar y superar las dificultades y renovarse para siquiera mantener la producción económica en el mejor nivel posible, o languidecer en la inacción esperando que las cosas mutaran favorablemente con el tiempo. 
Renovaciones de arrendamientos y restituciones coetáneas de terrenos

Las exitosas negociaciones de los años 1913, 1924 y 1938 referidas a las renovaciones de los arrendamientos de campos fiscales tuvieron una repercusión ingrata para la S.E.T.F. en lo tocante a su prestigio público y a la malquerencia popular (en Magallanes), sin otras razones que la del malestar que generaba el poder monopólico que detentaba, su formidable fuerza económica y su capacidad de influencia. Ello unido a la certidumbre de que la posesión y la explotación pastoril de los campos era una fuente de prosperidad y riqueza, bastó para coaligar a todos los sectores de la opinión magallánica ajenos a las grandes sociedades empresariales en una campaña de oposición a la renovación de los arrendamientos de que la Explotadora era titular para, sobre la base de los terrenos a recuperarse, generar y llevar adelante un proceso de subdivisión predial y de recolonización ganadera por parte de pequeños o medianos emprendedores capitalistas, que se esperaba fuera la gran palanca para un desarrollo renovado y el progreso de Magallanes. Esa fue en 1913 la gran divisa de la lucha ciudadana y lo sería nuevamente en ocasión de los sucesivos arrendamientos hasta 1957. Sí porque, no obstante el empeño cívico con respaldo popular evidente, más pudieron las vinculaciones sociales y políticas de la Explotadora y su inmejorable llegada a los gobiernos de derecha que rigieron a Chile hasta 1938. De esa manera, si los antirrenovacionistas no tuvieron el éxito que en cada oportunidad esperaron, tampoco la Explotadora pudo conseguir la magnitud fundiaria que deseaba. Por ello la superficie de campos fiscales en sus manos fue disminuyendo progresivamente. Pero, así, todo, en una política negociadora muy hábil de sus directores, la Sociedad consiguió extender sus arrendamientos de campos fiscales en la Tierra del Fuego hasta 1957, época en que el gobierno del Presidente Carlos Ibáñez del Campo -tras una última campaña popular- decidió la no renovación del saldo de tierras que hasta entonces había detentado la compañía. El siguiente cuadro da cuenta de la situación descrita:

Tabla 3.

\begin{tabular}{|c|c|c|}
\hline Año & Arrendamiento & Restitución al Fisco \\
\hline 1913 & 1.176 .000 & 221.000 has. \\
\hline 1924 & 950.000 & 226.000 “ \\
\hline 1938 & 707.385 & 242.165 “ \\
\hline 1957 & & 557.385 “* \\
\hline
\end{tabular}

150:000 de Cameron habían sido permutadas por 50.000 de propiedad de la S.E.T.F. en Ultima Esperanza.
Con la devolución del saldo final de los campos fiscales que había arrendado, el patrimonio fundiario de la Explotadora quedó compuesto únicamente por sus propiedades en Chile y Argentina donde en uno y otra habían aumentado. En efecto, entre 1911 y 1958 la Sociedad adquirió a diferentes propietarios campos en Última Esperanza y Magallanes centrooriental, de las que las más significativas fueron las estancias "Kimiri Aiken y "Ciaike" (102.833 has.) que pertenecían a The Patagonian Sheep Farming Company (1950), la estancia "Los Vascos" en el Territorio de Santa Cruz (Argentina) y la permuta hecha en 1958 con el Fisco de Chile, en cuya virtud la Explotadora entregó 50.000 hectáreas de su dominio en Ultima Esperanza (para satisfacer las antiguas demandas de sus habitantes) y recibió 150.000 de terrenos fiscales correspondientes a parte de la estancia "Cameron" en la Tierra del Fuego. Con todas esas adquisiciones su dominio enteró 1.296 .807 hectáreas, de las que 982.855 se hallaban en suelo chileno y 313.952 en el argentino.

\section{Innovaciones productivas y tecnológicas}

Si parte del desafío empresarial de recuperar la cabida perdida se pudo cumplir con las adquisiciones de terrenos en propiedad, era claro que sin embargo de ello había que hacer un esfuerzo tecnológico innovativo para enterar la meta autoasignada por la superioridad ejecutiva y el Directorio para enterar la capacidad productiva, en tanto que este aspecto se había visto afectado en el transcurso del tiempo por el solo efecto del pastoreo sobre los suelos esteparios (con pérdida de cobertura vegetal y exposición a meteoros climáticos como el viento). En los años finales de la década de 1950, por consecuencia, si importante era la voz de la experiencia, como era la tradición empresarial, también pasó a serlo la de los profesionales universitarios que podían aportar a tal propósito desde que dominaban un importante acervo de conocimientos empíricos que interesaba particularmente al último de los aspectos mencionados.

Los especialistas introdujeron entonces en el lenguaje corporativo conceptos tales como "recuperación de suelos" empobrecidos o naturalmente pobres, "siembra con especies forrajeras", "manejo racional de las pasturas", "aumento de la capacidad talajera", etc. 
Importa señalar que tal preocupación no era exclusiva de la Sociedad Explotadora de Tierra del Fuego, pues desde antes de la Segunda Guerra Mundial ello interesaba a importantes productores de otros países laneros como Australia, Nueva Zelandia, Sudáfrica y EE. UU.de América, y que al ser así ratificaba su buen prestigio empresarial como entidad de vanguardia tecnológica.

La necesidad de que se trata condujo a la contratación de profesionales de la agronomía con los que fue posible constituir un equipo o departamento técnico cuya tarea permitió formular en 1957 un Plan de Fomento de la Producción Ganadera, con una inversión de US\$ 3.500.000 (US\$2.000.000 en maquinarias, semillas y otros materiales y elementos; y US\$1.500.000 en obra de mano, construcciones especiales, personal técnico y varios) ${ }^{35}$. El objetivo era ambicioso: aumentar la dotación de las cinco estancias de su propiedad en Magallanes ("Cerro Castillo", "Cerro Guido"; "Bories", "Oazy Harbour" y "Punta Delgada"), cuya dotación en la época era de 554.500 ovinos, a 831.500 (50\% de incremento) en un plan de doce años, por la sola elevación de la producción forrajera en las áreas mejorables y la consiguiente aplicación de pastoreo diferido en el resto de las praderas naturales ${ }^{36}$.

Para 1959 la propuesta era considerada de desarrollo tan exitoso como para hacer de la misma un "Plan piloto" para la Región de Magallanes. Era, de modo cierto, una muy interesante perspectiva para la economía regional en la que por entonces la producción ganadera -lanera principalmentemantenía una fuerte preponderancia en lo referido a la generación del producto geográfico bruto.

De esa manera, las sucesivas memorias y balances empresariales fueron dando cuenta de los adelantos conseguidos, pudiéndose reconocer en los correspondientes a 1968 con la satisfacción que cabe imaginar, el cumplimiento de la meta propuesta en 1957 al registrarse entonces una dotación de 1.039.001 ovinos, con una producción de 10.003.322 libras de lana (el máximo nivel de rendimiento promedio por cabeza había sido alcanzado en 1965). Ello era un logro digno de admiración

35 Mario Habit "Empastadas y mecanización agrícola en Magallanes" (Boletín Ganadero №. 72, Punta Arenas, abril de 1959), pág. 4.

36 Id. Pág. 5. en cuanto significaba cantidad (dotación) y calidad (rendimiento en lana).

Pero la innovación no había parado en ello sino que, asimismo, se había extendido a otro tipo de crianza hasta entonces virtualmente marginal como era la de los vacunos, cuya dotación se había mantenido históricamente en rangos numéricos bajos y poco variables que promediaban entre cinco y seis millares de cabezas hasta 1959.

Así, a base de la recomendación técnica respecto del mejor y más racional aprovechamiento de las pasturas (pastos altos) se decidió aumentar la explotación bovina incorporando animales de calidad productiva cárnea probada y facilidad de manejo, como era la raza Hereford. En consecuencia en 1964 la Sociedad adquirió en Australia un plantel de animales de alta selección, con una inversión de US\$ 350.000. De tal manera, un lustro después la dotación bovina histórica había sido casi triplicada con ganado de mejor calidad. Fue ese otro acierto tecnológico y económico pecuario que dio principio histórico a la crianza bovina masiva en Magallanes y en la Patagonia entera, territorio tenido hasta entonces por exclusivamente ovejero. ¡Sencillamente asombroso!

Estas iniciativas, debidamente apreciadas por el gobierno del Presidente Eduardo Frei Montalva, hicieron merecedora a la Sociedad del reconocimiento especial de "Cooperadora del Plan de Desarrollo Ganadero" nacional (Decreto Supremo N 628 del Ministerio de Agricultura, 1965).

La exitosa aclimatación de la raza Hereford y las perspectivas de su crianza para la diversificación de la producción agropecuaria movieron al Gobierno Regional de la época, que por entonces presidíamos, a recomendar al Ministerio de Agricultura el respaldo para la iniciativa de que se da cuenta. Tuvo origen así, con la intervención de la Corporación de Fomento de la Producción como agente a cargo, la importación de sucesivas partidas de animales bovinos de esa raza desde los Estados Unidos de América (los primeros llegados por vía aérea), medida que afirmó el desarrollo bovino hasta alcanzar su bien prestigiado actual nivel.

Pero si de innovación económica se trataba, la antigua Sociedad Explotadora dio entonces otro paso que de primera pudo ser mirado como atrevido y al fin, por sus resultados, tenido como un nuevo acierto: la explotación del turismo como una activi- 
dad económica de interés y de futuro. Y ello se hizo valorándoselo como rubro económico de posibilidad cierta en una región como la de Magallanes admirablemente dotada de recursos naturales para una explotación de gran envergadura y con perspectivas de seguro desarrollo. La propuesta apuntó a un elemento básico para tal explotación, la necesidad de disponer de infraestructura hotelera de corte moderno sobre la cual fundar un ulterior negocio del ramo. Una visión empresarial excepcional, en verdad pionera.

Cabe una reflexión particular sobre lo expuesto.

En una entidad tan jerarquizada como lo era la Explotadora, nada podía hacerse sin que ello se originara en, o se autorizara por el directorio de la misma, instancia en que los diferentes integrantes representaban al accionariado más importante, salvo que, cosa lógica, la plana técnica superior recomendara la adopción de medidas significativas de inversión en orden a mantener la producción económica en los estándares de calidad tradicionales, a recuperarla cuando se dieron contingencias que la afectaron o, inclusive, a mejorarla si tal era posible. Pero los vientos de cambio de la época sensibilizaron a algunos directores en lo tocante a materias que podían ser diferentes bien porque se apartaban del rubro tradicional de actividad, bien porque decían con lo social en cuanto a su énfasis, o respecto de una nueva forma de conducir los negocios. De ese modo los aires progresistas, por calificarlos de algún modo, llegaron hasta la alta esfera directiva encontrando en algunos de sus integrantes una disposición de apertura para acogerlos y obrar en consecuencia. No en todos, ciertamente, pues otros directores optaron por posiciones más apegadas a la tradicional mesura, esto es, posturas más conservadoras.

Ocurrió que con la década de 1960 la posición aperturista pudo ser mayoritaria y consiguió establecer planteamientos en los que se fundaron algunos cambios en la gestión y orientación empresariales, entre ellos uno de trascendencia como sería la nominación para el cargo de gerente general a un profesional talentoso que no había hecho carrera en la compañía, con lo que se rompía una tradición caracterizadora: el ingeniero comercial Danilo Poklepovic, ligado por parentesco con Pedro Poklepovic, Presidente de la Sociedad y entonces también senador de la República por el Partido Liberal. Este hombre ajeno al staff corporativo asumió la responsabilidad de endilgar con impulso de creatividad renovadora el rumbo social por vías de modernidad.

\section{La renovación de la imagen social}

El cómo había podido darse aquello de lo que se ha dado cuenta decía, mucho, con la renovación de la imagen pública de la Sociedad, harto vapuleada a lo largo de su vigencia y más en época reciente cuando se había enfrentado la renovación del arrendamiento fueguino.

De partida, cabía modificar el nombre con el que se la había designado al tiempo de la fundación. Se había soportado por décadas el sambenito de "Explotadora", que si no era oprobioso sí era incómodo, y pasada la mitad del siglo XX se pensaba por algunos ejecutivos y directores que era el tiempo de cambiar la denominación social al amparo de las ideas de innovación y modernización que campeaban en la empresa. La oportunidad para ello la brindó la reforma del estatuto social realizada en 1964, tras la que se adoptó el nombre de GANADERA TIERRA DEL FUEGO S.A., denominación que por largo tiempo contendería en la memoria colectiva con la antigua a la que, por lo demás, prácticamente nunca lograría desplazar totalmente.

Pero tal no bastaba, por cierto, y había que afirmar la voluntad de cambios en profundidad que se gestaban y desarrollaban, para que tanto la sustancia como la imagen se correspondieran. Si así lo expresaban desde antes las innovaciones técnicas, el plan de fomento ganadero y la extensión de su actividad al rubro turístico, era menester continuar por esa vía, afirmando las realizaciones.

Desde luego enfatizar la preocupación por lo social y en lo concreto por la edificación de viviendas para su personal obrero, con lo que podía acallarse la tan repetida afirmación de que a la Sociedad lo único que le había interesado siempre eran sus ganancias y el reparto de utilidades a los accionistas, sin que en el territorio que las generaba quedara algo en beneficio de su gente que contribuía a generarlas con su esfuerzo y trabajo. En buenas cuentas, se trataba de inversiones de tipo social, no retributivas económicamente. 
La primera señal se había dado luego de la Asamblea General de Accionistas de 15 de septiembre de 1951 en la que se propuso por el directorio y se aprobó por aquélla la creación de una "Reserva especial para Habitaciones Obreras" (250.000 libras esterlinas); para edificar tres conjuntos de viviendas en Punta Arenas, Puerto Natales y Porvenir. De este plan sólo se ejecutó la parte correspondiente a la capital regional, que era la más importante como proyecto, al inaugurarse en 1953 la "Población Explotadora" 37 con una inversión ligeramente superior a las 200.000 libras esterlinas.

Con todo la comunidad regional no quedaría satisfecha, pues aunque se apreciaba lo realizado se lamentaba la discontinuidad del plan habitacional, por lo que el siguiente paso empresarial fue el de planear y construir un gran edificio para un hotel como infraestructura básica para el desarrollo turístico regional, obra visualmente impactante como manifestación de la renovación del ramo y de modernización del casco urbano central de Punta Arenas. Su construcción se inició en 1960 y fue inaugurada en septiembre de 1962 en medio del unánime reconocimiento ciudadano. Con el correr del tiempo el edificio del hotel "Cabo de Hornos" ha devenido un ícono de la renovación inmobiliaria de Punta Arenas ${ }^{38}$.

La preocupación social se manifestó coetáneamente también en otros aspectos como fueron la creación de "pensiones voluntarias de gracia" para los trabajadores de la Sociedad y de "becas especiales" para que sus hijos prosiguieran estudios universitarios o técnicos, además de "becas escolares" (para estudios primarios y secundarios) y de otros beneficios de data anterior (asignaciones de natalidad y de nupcialidad, movilización gratuita, carne barata, beneficios de pulpería, etc.). A título de referencia en el trienio 1967-69 se concedieron 324 pensiones voluntarias, 345 becas especiales y 4.086 becas estudiantiles. Por fin, en especial a contar de 1960 se realizaron inversiones en la habilitación de escuelas e internados, de bibliotecas, postas sanitarias, casinos y clubes en los diferentes establecimientos rurales, como complemento de otras

37 El nombre se ha mantenido hasta el presente como identificación del conjunto y de su entorno edificado.

38 Tal calificación le fue dada oficialmente con motivo de la celebración del Bicentenario de la República en 2010. inversiones en habitaciones anteriores o coetáneas, que en conjunto contribuyeron significativamente al bienestar y calidad de vida de los trabajadores de la Sociedad.

Aun en la más estricta apreciación de esta conducta empresarial, en lo tocante a su suficiencia, es preciso convenir en que la situación de la Explotadora era, lejos, superior por donde se la considerara en comparación con cualquier otra entidad patronal en el mundo agrario nacional de la época.

Pero y sin embargo de la importancia que de suyo tiene todo lo anterior, tal vez el cambió más llamativo de ese período fue la "chilenización" de su plana ejecutiva y operativa gracias a los ascensos y a la contratación de personal de origen nacional, en particular de profesionales y técnicos universitarios. De esa manera, en 1968 la 75a. Memoria Anual incluía la nómina de esa plana (23 personas) en sus diferentes niveles (Gerencia, Sub-Gerencias, Inspección General, Jefatura Departamento Técnico, Contraloría, Contaduría General; apoderados y asesores; y Administración de estancias). De ellos, los chilenos eran 21 y sólo dos administradores de estancias eran extranjeros. Vale decir, un cuadro diametralmente distinto al que regía un cuarto de siglo antes, en 1943, época del cincuentenario de la gran compañía.

Una mutación ciertamente significativa, tal como lo demandaba el tiempo que se vivía que era de exigencias en diferentes respectos.

\section{EL FIN: LA EXPROPIACIÓN DEL DOMINIO FUNDIARIO (1970-72)}

La reforma agraria no estuvo incluida entre los objetivos del gobierno de Eduardo Frei Montalva para Magallanes. En verdad, la situación rural de la región era distinta, para mejor, de la archiconocida para el sector agrario de la zona agrícola del país (desde el Norte Chico hasta Llanquihue) Fuera porque en Magallanes el empresariado rural tenía mayor conciencia de responsabilidad social, fuera porque los trabajadores tenían una larga tradición de sindicalización y de defensa de sus derechos, o por ambas razones, se había generado una situación de conformidad con el estado de cosas vigente, de ahí que la expropiación de tierras latifundiarias no estaba en el sentimiento colectivo, menos todavía en el de los campesinos a los que, por lo demás, el sistema 
de trabajo rural conformado desde muy antiguo les contentaba más allá de ocasionales reclamos y demandas. Los trabajadores del campo magallánico (como los de la totalidad del ámbito patagónico) eran "apatronados", término del lenguaje popular que manifestaba la aceptación o conformidad con el sistema $^{39}$. Tampoco cabía, por todos los antecedentes conocidos, una eventual causal de expropiación por razón de ineficiencia productiva pues, precisamente, si algo prestigiaba al empresariado magallánico era su buen -y en el caso de la Ganadera, excelenteestándar productivo, al que lo único que podía reprochársele era su carácter latifundiario.

Así, la inclusión de la política de reforma agraria en el ámbito de las preocupaciones locales fue cosa del gobierno regional de Magallanes, como una necesidad de fomentar el desarrollo rural para fomentar el poblamiento y la mayor y más eficaz integración de sus diferentes sectores al proceso general de crecimiento socio-económico, que se había planteado como meta antes de la elección presidencial de 1964. Estaba, además, la noción de encontrarse en Magallanes el mayor latifundio del país y que por tanto bien valía una medida como la expropiación que siendo ejemplarizadora sirviera, así se pensaba, como estímulo para completar la modernización agraria con mejores estándares productivos y mejores calidad de vida y trabajo para el campesinado dependiente.

De esa manera la decisión de iniciar el proceso de aplicación de la reforma agraria en Magallanes, se reitera, fue inducida por el gobierno regional y aceptada por los niveles responsables del gobierno nacional y de la Corporación de la Reforma Agraria. En los casos iniciales (estancias "Bellavista", "Laguna Blanca-Wagner" y "Peckett Harbour") había buenas razones, pues tales predios pertenecían a sociedades cuyos accionistas propietarios residían fuera de la región o del país y que, además, en su manejo operativo seguían una invariable rutina tradicional ajena a cualquier innovación. Pero ello no pareció ser suficiente y se impuso el convencimiento de que la mayor propietaria rural, la Ganadera de Tierra del Fuego S.A. (antigua S.E.T.F.) debía ser tocada

39 Debe reiterarse que cuando el gobierno del Presidente Frei decidió la expropiación de la estancia "Punta Delgada", la única voz que se opuso a la medida fue la de los trabajadores del mismo predio que habría de ser afectado por la medida. siquiera en uno de sus grandes predios tan sólo por su magnitud areal y no obstante que en cuanto al manejo y presencia empresariales no se daban en su respecto las circunstancias aplicables a las otras empresas afectadas con antelación (sociedades familiares Arnaud y Wagner Seiffert y Sociedad Ganadera y Comercial Sara Braun).

Tal excepcionalidad, precisamente, fue la que motivó una consideración especial para la situación de la .Ganadera habida cuenta de sus planes concretos de desarrollo agrario y sus resultados satisfactorios que le habían significado el reconocimiento oficial como cooperadora del Estado en la importante materia. Por ello, valorándose su importancia en la actividad económica y en la vida de Magallanes se discurrió una suerte de alternativa que pretendía favorecer a la poderosa compañía: la de convenirse con ella en la realización de una "expropiación pactada" que permitiera al Gobierno llevar adelante sus planes de fomento regional y a la Ganadera proseguir con sus propios planes de desarrollo, con la garantía de inexpropiabilidad del resto de su vasto dominio fundiario.

En efecto, a comienzos de 1965, como hemos escrito antes, ejecutivos de la Corporación de la Reforma Agraria y el Intendente de Magallanes iniciaron negociaciones con el directorio de la compañía a fin de pactar la expropiación selectiva de un tercio de su dominio (331.617 has.), garantizándosele a cambio la intangibilidad del resto donde radicaban sus principales inversiones, por un lapso razonable como para permitir su recuperación. Tras varios meses de conversaciones fue imposible llegar a un acuerdo, circunstancia que dejó a la Corporación en libertad para proceder según lo aconsejaran las circunstancias.

No deja de sorprender la falta de visión de la dirigencia empresarial, cuya perspicacia había sido proverbial. Apostó a su capacidad de influir en el más alto nivel del gobierno y perdió. De haberse obrado con prudente consecuencia, según se iban dando las cosas en el país, quizá no se habría podido revertir el proceso en cuanto se afectaban los intereses fundiarios de la compañía, pero sí se habría conseguido su inserción dentro del mismo con propuestas de desarrollo socioeconómico acordes con las exigencias del tiempo, pero se impusieron la estrecha visión y el cálculo errado de la mayoría de sus directores, por sobre las advertencias de 
proceder con dominio de la realidad. Así se dejó pasar, definitivamente, una oportunidad única. ${ }^{40}$

En el directorio de la Ganadera de Tierra del Fuego S.A. el ambiente estaba dominado por la opinión de quienes, como Recaredo Ossa expresidente de la Sociedad Nacional de Agricultura, eran conocidos y enconados opositores a la reforma agraria y a toda manifestación de progresismo en el manejo de las actividades empresariales, y que por tanto no deseaban contemporizar con un gobierno como el del Presidente Frei al que miraban como opuesto a sus intereses.

Como en ocasiones los males suelen venir en tropel, también por entonces la Ganadera debió recibir otro golpe, quizá tan inesperado como el de la expropiación de la estancia "Punta Delgada". El mismo provino del Gobierno Argentino y afectó a sus propiedades en la Provincia de Santa Cruz. La motivación ahora no se dio por razones ideológicas como en Chile, sino de carácter geopolítico, pues molestaba a los gobiernos de facto militares de la época en Argentina que una sociedad chilena (por capital, domicilio y gestión) tuviera campos en su territorio, más si eran en parte fronterizos con los que aquélla poseía en suelo chileno. De esa manera, derechamente se exigió a la Ganadera de Tierra del Fuego S.A. la enajenación de sus dominios argentinos a entidades del género que tuvieran radicación en el país y se gestionaran con autarquía en el mismo. $\mathrm{Y}$ así se hizo.

Sobre los campos expropiados en Magallanes entre 1966 y 1970 se estableció por la Corporación de la Reforma Agraria la modalidad operativoproductiva de los "asentamientos de la Reforma Agraria". La novedad en su operación estuvo en la incorporación de medidas de desarrollo social sugeridas por el gobierno regional de Magallanes tendientes a lograr el fomento de la vida rural mediante el poblamiento y la creación de otras actividades productivas, y la integración de los distritos rurales al proceso general de desenvolvimiento y adelanto que se realizaba en la región.

Las elecciones presidenciales de 1970 dieron el triunfo al candidato Salvador Allende apoyado por el conglomerado político denominado Unidad Popular, que postulaba medidas diversas de tipo

40 Historia de la Región Magallánica Ediciones de la Universidad de Magallanes 2006 (1992), tomo IV, pág. 1420. radical en lo económico, lo político y lo social. Así, en lo tocante a la reforma agraria, el proceso iniciado durante el gobierno de Frei se completó en todo Chile. En Magallanes ello significó la expropiación de todas las propiedades rurales grandes y medianas, de las que la Ganadera de Tierra del Fuego S.A. era la mayor poseedora. Para entonces la situación de que se trata no tenía vuelta, pero nos preguntamos si la hubiera tenido en el caso de haber pactado la Sociedad con el Estado en el sentido antes mencionado.

En lo que interesa, sobre tan vasto dominio se constituyeron las Sociedades Agrícolas de Reforma Agraria (SARAS) y los Centros de Reforma Agraria (CERAS), a razón de uno de ellos por cada estancia según los casos, cuyo manejo operativo dio origen a una suerte de "democracia participativa" en la que todas las opiniones eran igualitarias lo que como puede imaginarse generó desorden, descoordinación y al fin a una gestión desastrosa. Sin ambigüedades afirmamos que en Magallanes la reforma agraria fue un fracaso.

Cosa curiosa, considerada con perspectiva histórica la política de reforma agraria en la zona agrícola de Chile central donde se aplicó (desde Coquimbo a Llanquihue), además de los profundos y decisivos cambios que introdujo en lo social, en el dominio rural y en lo económico, tuvo un efecto no deseado como fue el de la modernización de la agricultura -hecho que hoy en día nadie cuestiona- al punto de ser la misma el fundamento de una potencialidad productiva agroindustrial de notables resultados, bien conocida a través del eslogan "Chile, potencia agroalimentaria".

Para Magallanes (y vale lo mismo para Aysén), en cambio, la experiencia de la reforma agraria fue la de un fracaso completo como expresión de gestión económica operativa y que se reflejó a poco andar en el descenso notorio de la cuantía y en la inferior calidad de la producción.

Como manifestación de progreso social fue de efectos limitados pues sólo permitió mejorar los ingresos y niveles de vida de unos pocos campesinos (los antiguos asentados, después cooperados). Tocante al primer aspecto, la gestión incompetente condujo al descuido del suelo, agravando una situación que ya se venía manifestando desde largo tiempo antes, con reducción de la capacidad talajera de los campos, la disminución cuantitativa y cualitativa de 
la masa ovina ${ }^{41}$, el deterioro de las instalaciones y la pérdida de parte del riquísimo acervo acumulado por la experiencia secular en materia de manejo ovejero. Casi un descalabro del que la Región conseguiría recuperarse parcialmente al cabo de varios lustros, hasta estabilizarse en un nivel de cualquier modo inferior al conocido para el mejor tiempo de la ganadería magallánica hasta 1970 .

La situación de que se trata condujo, tras el golpe de Estado de 1973, al proceso de contrareforma agraria y al rediseño del tamaño económico rentable de las unidades de producción, mediante el que se dio comienzo y forma al proceso de reordenamiento y recuperación de la actividad ovejera regional. En esta etapa, los beneficiarios no siempre pudieron responder a las exigencias y fueron muchos los que por causa de una administración técnica inapropiada, fruto del insuficiente conocimiento o de la inexperiencia, y de la insolvencia económica ante la imposibilidad de servir los créditos bancarios conseguidos, debieron enajenar sus propiedades a terceros o dejarlas derechamente en manos de las instituciones financieras acreedoras.

Ello condujo a la larga a un proceso de concentración de propiedades rurales en pocas manos en determinados sectores del ecúmene (Última Esperanza, Magallanes centro-oriental y centro-sur de Tierra del Fuego). Como, por otra parte, las cooperativas de la reforma agraria se vieron afectadas o por situaciones de insolvencia económica (créditos bancarios) o por la incapacidad de sus miembros para renovar su integración (sucesiones en la titularidad de la participación en las cooperativas), en el curso de los años transcurridos las mismas acabaron por ser vendidas como un todo, al punto que de la mayor parte de las siete constituidas para $1970^{42}$,

41 Para fundar la afirmación basta ejemplarizar con las cifras censales agropecuarias. Así, el Censo Nacional Agropecuario de 1965 registró un total de 2.779.237 cabezas ovinas en Magallanes, que sería la mayor cantidad histórica de la actividad (y que con el desarrollo de la época pudo estimarse en unos 3.000.000 de animales para 1970). El Censo Nacional Agropecuario de 1985 arrojó un registro de 2.128.300 cabezas ovinas, en una etapa que se consideró era de recuperación. Huelgan los comentarios.

42 "Cacique Mulato", "El Ovejero", "Estrecho de Magallanes", "Ciaike", "Bernardo O'Higgins" y "Cañadón Grande", surgidos del proceso de reforma agraria, a los que se añadió "Timáukel", formado sobre la base de terrenos fiscales que se habían sido ocupados por la estancia "Cameron", en Tierra del Fuego. al presente (diciembre de 2010) sólo queda vigente la de "Cacique Mulato", respecto de la cual pocos dudan en que la misma podría acabar vendiéndose al capitalista que mejor pague por la propiedad rural. Esta sucesiva mutación en la tenencia agraria durante el tiempo reciente para concluir en un fenómeno que apunta nuevamente a la concentración del dominio en forma de unidades productivas de gran extensión areal ${ }^{43}$, lleva a preguntarse acerca de qué tanto valió la pena el esfuerzo precedente sobre el que se ha dado cuenta.

Privada de sus tierras, la Ganadera no tenía razón para prolongar su vigencia; cabía pues su disolución y a ello se procedió durante 1973 ante la impasibilidad de la comunidad que pareció no condolerse por el acontecimiento ${ }^{44}$. Lo que había sido su octogenaria existencia pasó a ser desde entonces dominio exclusivo de la historia.

\section{EL LEGADO DE LA SOCIEDAD EXPLOTADORA DE TIERRA DEL FUEGO}

Corridas casi cuatro décadas, desde tal decisión es tiempo de preguntarse sobre cuál pudo ser el legado de la otrora omnipresente y omnipotente entidad. Ciertamente que lo hay y sobre ello cabe abundar.

De partida, a la Sociedad Explotadora de Tierra del Fuego debe reconocérsele sin discusión el mérito de haber inspirado y logrado el elevado estándar histórico de la producción ovina magallánica, cimentando su prestigio dentro y fuera del país; del mismo modo que el de haber introducido

43 No faltan defensores para este proceso, quienes afirman que esa es la única forma de hacer realmente rentable la explotación ganadera, incluyendo la recuperación de las antiguas y bien probadas formas de trabajo ganadero.

44 Cabe recordar aquí, a propósito, un hecho del que fuimos participes. En efecto en uno de esos días finales nos llamó un antiguo empleado, entonces a cargo de la gran bodega donde se depositaban la documentación y otros elementos de la Sociedad, para infórmanos que había recibido la orden de quemar todos los papeles y antes de proceder a ello le pareció oportuno y prudente interesarnos en el rescate de aquello que pudiera ser útil para la historia regional. En inmediata decisión concurrimos al local y seleccionamos con la comprensible premura volúmenes y legajos correspondientes a los tiempos iniciales de la actividad de la Explotadora, que conformaron la base del posterior Archivo de Documentos Inéditos del Centro de Estudio del Hombre Austral del Instituto de la Patagonia, que ha sido, como es, de tantas utilidad para los estudios e investigaciones históricas. 
la crianza bovina para la producción de carne como rubro significativo de la actividad agropecuaria regional. Consecuencia de ello, en lo que ha sido otro de sus aportes a la posteridad, dejó una cultura tecnológica de trabajo y producción responsable y eficiente, especialmente en el ramo de la crianza ovejera, prestigiada por su seriedad y resultados que han hecho de la misma un paradigma de la actividad para el país.

En otro orden dicha entidad dio origen y forma a un estilo de conducción empresarial caracterizado por la valoración y preservación del trabajo humano como factor esencial en la producción agraria, y que a lo largo de su existencia histórica conformó un ejemplo de buen manejo laboral.

Asimismo, y no menos importante, cabe apreciar como un auténtico legado el tradicional buen uso que dicha entidad hizo de los recursos del suelo, manifestación de su compromiso con el ambiente natural y su sustentabilidad, aspecto en el que la desaparecida compañía fue sin duda pionera en la región y en el país.

Finalmente, más que un legado, ha sido la sensación de vacío la que ha permanecido en el ánimo de la comunidad regional por la desaparición de una entidad empresarial que fuera una protagonista calificada y de vanguardia en la producción agraria de Magallanes, vacío que no ha sido llenado por otra capacidad operativa de semejante envergadura y vigor.

\section{FUENTES DE CONSULTA}

a) Inéditas

ALVAREZ VERA, N. S/fecha Un campesino le escribe a Su Excelencia: el desahucio político, una figura amparada por nuestra legislación laboral. Valparaíso.

FUENZALIDA, A. 2005 El perro ovejero magallánico: Testimonio de reconstrucción histórica. Trabajo de Seminario, Instituto de Historia, Facultad de Historia, Geografía y Ciencias Políticas, Pontificia Universidad Católica de Chile, Santiago.

b) Impresas

CHAPARRO RUMINOT, M. 1917 Estudio Económico-Administrativo-Social del Territorio de Magallanes. Santiago.

FUENTES RABE, C. 1923 Tierra del Fuego. Valdivia.
GANADERA TIERRA DEL FUEGO S.A. 1967 Memoria Anual. Valparaíso.

1968 Memoria Anual. Valparaíso.

1969 Memoria Anual. Valparaíso.

HABIT C., M. 1959 Empastadas y mecanización agrícola en Magallanes. Boletín Ganadero No. 72. Punta Arenas

JONES, T. P. 1961 Patagonian Panorama. London.

DURAN, F. 1943 Sociedad Explotadora de Tierra del Fuego. Santiago.

BASCOPE, J. 2008 Pasajeros del poder propietario. La Sociedad Explotadora de Tierra del Fuego y la bio-política estanciera (1890-1920). Magallania 36(2): 19-44. Punta Arenas.

MARTINIC B., M. 1982 La Tierra de los Fuego Municipalidad de Porvenir. Punta Arenas.

1983. Ultima Esperanza en el tiempo. Ediciones de la Universidad de Magallanes. Punta Arenas.

1986. Nogueira el pionero. Ediciones de la Universidad de Magallanes. Punta Arenas.

2001. Menéndez y Braun. Prohombres patagónicos. Ediciones de la Universidad de Magallanes. Punta Arenas. 2006 (1992) Historia de la Región Magallánica. 4 tomos. Ediciones de la Universidad de Magallanes. Punta Arenas.

2001. El ordenamiento rural en Magallanes, 1894-1973. La dirección y manejo de las grandes estancias. En: Vida Rural en Chile durante el siglo XIX. Academia Chilena de la Historia. Santiago.

2009. Los comienzos del transporte mecanizado terrestre en Magallanes (1900-1930). Magallania, 37(1): 7-20. Punta Arenas.

SERRANO MONTANER, R. 1935 La chilenización de Magallanes. Revista Chilena de Historia y Geografía, tomo LXXVII. Santiago.

SOCIEDAD EXPLOTADORA DE TIERRA DEL FUEGO Memorias y Balances años 1909, 1915, 1917, 1919, 1920, 1924, 1928, 1938, 1940, 1941, 1942, 1943, 1944 1945, 1946, 1947, 1948, 1949, 1950, 1951, 1952, 1953, 1954, 1956, 1961, 1962, 1963. Valparaíso. SOCIEDAD EXPLOTADORA DE TIERRA DEL FUEGO 1915 y 1917 Nómina de Accionistas. Valparaíso.

TRINCADO, R. 2002 Seis caballos y un Winchester Santiago.

c) Entrevistas

RUIZ SANTANA, GUILLERMO 2010 Entrevista realizada a los señores Félix Dillems, Ernesto Pérez Castañón y Ricardo Livingston Bianchi. Puerto Natales. 